\title{
Cyclic hardening/softening experimental data in nano-clay-composite and aluminum alloy under high-temperature strain-controlled loading
}

\author{
Mohammad Azadi $^{1 \star *}$ (D), Hamed Bahmanabadi ${ }^{1}$ (D), Florian Gruen ${ }^{2}$, Gerhard Winter ${ }^{2}$ and \\ Benjamin Seisenbacher ${ }^{2}$ \\ ${ }^{1}$ Faculty of Mechanical Engineering, Semnan University, Semnan, Iran, and ${ }^{2}$ Chair of Mechanical Engineering, Montanuniversität \\ Leoben, Leoben, Austria \\ ${ }^{*}$ Corresponding author. Email: m_azadi@semnan.ac.ir
}

(Received 06 October 2021; Revised 22 November 2021; Accepted 06 December 2021)

\begin{abstract}
This article presents cyclic hardening/softening behaviors (experimental data) of the heat-treated aluminum-matrix nano-clay-composite (AlSi_N_HT6), compared to those of the piston aluminum alloy (AlSi) under strain-controlled loading. For such an objective, standard samples were fabricated by gravity and stir-casting methods. Low-cycle fatigue experiments were carried out under different strain amplitudes $(0.20-0.45 \%)$ and at various temperatures $\left(25-300^{\circ} \mathrm{C}\right)$. Obtained results implied that no obvious change was observed on material properties of aluminum alloy by reinforcements, but a decrement was observed due to increasing the temperature. Results also indicated that the increase of the temperature from $25^{\circ} \mathrm{C}$ to $200^{\circ} \mathrm{C}$ has changed the cyclic behavior of both materials (AlSi_N_HT6 and AlSi) from hardening to softening. Moreover, the temperature effect was more significant than the total strain amplitude influences in cyclic behaviors.
\end{abstract}

Key words: aluminum alloy; cyclic experimental data; low-cycle fatigue; nano-composite; strain-controlled loading

\section{Introduction}

Engine components are usually exposed to cyclic loadings at elevated temperatures, such as pistons and cylinder heads. In these parts, aluminum-silicon alloys have been widely used, due to their proper mechanical and fatigue properties, as advantages of the material. Therefore, to design such engine components, knowing the cyclic behaviors of such materials is essential for engineers. However, aluminum alloys have low strength at high temperatures as a disadvantage that should be improved. There are various approaches for such an objective and one of the reinforcing methods is the addition of nano-particles.

Research studies on cyclic behaviors of aluminum alloys have been widely published since 2010 . As an example, Song et al. (2011) investigated the cyclic stress-strain behavior and the low-cycle fatigue (LCF) lifetime of the cast A356 aluminum alloy. They reported the cyclic hardening behavior for the material. Similar to this work, presenting the cyclic behavior of aluminum alloys could be found in the literature by Azadi (2013), Azadi and Shirazabad (2013), Do Lee and Yoo (2014), Kim et al. (2015), Azadi (2017), and Azadi et al. (2020). Branco et al. (2019) studied the strain ratio influence on the cyclic deformation behavior of the 7050-T6 aluminum alloy. Their results illustrated that the material depicted cyclic 
strain-softening, which increased when the strain ratio increased and the strain amplitude decreased. Cai et al. (2018) presented the temperature-dependent cyclic behaviors and the material microstructure of the $\operatorname{AlSi10Mg}(\mathrm{Cu})$ aluminum alloy. They claimed that $\mathrm{Mg}$-Si precipitates were the reason for cyclic hardening in the as-received alloy, due to the pinning effect. Li et al. (2018) investigated the influence of isothermal and non-isothermal aging on the LCF behavior of the forged $\mathrm{Al}-\mathrm{Cu}-\mathrm{Mg}$-Si aluminum alloy. They demonstrated that the material exhibited cyclic stability, compared to cyclic hardening of the heattreated samples.

\section{Objective}

As a conclusion on the literature review, the effect of different parameters such as the strain amplitude and the strain rate were studied on cyclic hardening/softening of aluminum alloys. In this research, the temperature effect was also added as a novelty. Besides, a heat-treated nano-composite, as a newly developed material, was suggested for engine pistons. Then, its cyclic hardening/softening was measured during strain-controlled fatigue testing, compared to that of the aluminum alloy. Such a casted aluminum alloy has been widely used in engine pistons.

\section{Methods}

The chemical composition of the piston aluminum-silicon alloy, which is used in this research, was included $13 \%$ wt. Si, $1 \%$ wt. Cu, and $1 \%$ wt. Mg. Aluminum bars were melted at $700^{\circ} \mathrm{C}$ and then, the nanocomposite was fabricated by adding $1 \%$ wt. of pre-heated $\left(\right.$ at $400^{\circ} \mathrm{C}$ ) nano-clay-particles (montmorillonite $\mathrm{K} 10$ ) into the aluminum matrix. This job was done $2 \mathrm{~g}$ by $2 \mathrm{~g}$ (to avoid the gas accumulation in the melt), with the stir-casting process. All casted cylinders were left in the free air at $23^{\circ} \mathrm{C}$, to be quenched.

The LCF standard specimens were machined and then, a T6 heat treatment, including solutioning at $500^{\circ} \mathrm{C}$ for 1 hour, water quenching, and aging at $300^{\circ} \mathrm{C}$ for 2 hours, was done on the material. More details of the sample production process could be found in Azadi et al. (2020).

LCF testing was done under strain-controlled loading conditions, with the $10 \mathrm{kN}$ servo-hydraulic Instron device. The mechanical strain amplitude was $0.20 \%, 0.25 \%, 0.30 \%, 0.35 \%, 0.40 \%$, and $0.45 \%$. The temperature was $25^{\circ} \mathrm{C}, 200^{\circ} \mathrm{C}, 250^{\circ} \mathrm{C}$, and $300^{\circ} \mathrm{C}$. It should be noted that the strain amplitude and temperature were constant during the tests. The strain rate was $1 \% / \mathrm{s}$ and the strain ratio was -1 , based on the E606 ASTM standard. The specimens were heated up using a 10-kW medium frequency generator for high temperature During LCF testing, the temperature was measured using $3 \mathrm{~K}$ type thermocouples. The strain was also measured by Instron room-temperature and MTS high-temperature extensometers for LCF tests at room and elevated temperatures, respectively. In addition to the fatigue test, the uniaxial tensile tests were performed to investigate the material properties of the samples at different temperatures using the $100 \mathrm{kN}$ servo-hydraulic Instron device, based on the E8M ASTM standard. More details of testing could be found in Azadi et al. (2020).

\section{Results and discussion}

To investigate the amount $\left(A_{\mathrm{H} / \mathrm{S}}\right)$ and the rete $\left(R_{\mathrm{H} / \mathrm{S}}\right)$ of cyclic hardening/softening of the material under LCF tests, Equations (1) and (2) were used, respectively,

$$
\begin{gathered}
A_{H / S}=\frac{\sigma_{\text {max }, \text { mid }}-\sigma_{\text {min }, 1 \mathrm{st}}}{\sigma_{\max , 1 s t}} \times 100, \\
R_{H / S}=\frac{A_{H / S}}{N_{f, \text { mid }}}
\end{gathered}
$$


where $\sigma_{\max }$ is the maximum stress and $N_{\mathrm{f}, \text { mid }}$ is the mid-life cycle of the specimen.

The Ramberg-Osgood relation was used as follows:

$$
\varepsilon=\frac{\sigma}{E(T)}+\left(\frac{\sigma}{k^{\prime}(T)}\right)^{1 / n(T)}
$$

where $\varepsilon$ and $\sigma$ are the total strain amplitude and the stress amplitude at mid-life cycle, $k^{\prime}(T)$ and $n^{\prime}(T)$ are temperature-dependent material properties or constants.

It should be noted that in this article, the word "AlSi" indicated the unreinforced specimen, and the word "AlSi_N_HT6" indicated the reinforced specimen.

Figures 1 and 2 depict material properties for AlSi_N_HT6 and AlSi samples under tensile loadings. If the Ultimate tensile strength (UTS) over the Yield strength (YS) is greater than 1.4, the cyclic hardening trend will occur and then, if such a ratio is less than 1.2, the cyclic softening behavior will occur. The ratio of the UTS to the YS for strengthened and un-strengthened samples at various temperatures is represented in Table 1.

In the second section, cyclic behaviors of materials are represented in Figures 3-17. Stress enhancing during cycles at room temperature was observed, which demonstrated the cyclic hardening behavior for both AlSi_N_HT6 and AlSi. Moreover, the AlSi sample exhibited the cyclic hardening trend at $200^{\circ} \mathrm{C}$. However, at this temperature, cyclic softening was seen in AlSi_N_HT6. The cyclic hardening amount was lower at lower values of the strain amplitudes. It seems that the temperature influence was more effective than the total strain amplitude influence to change from the cyclic hardening behavior to the cyclic softening trend. It should be noted that the cyclic trend had no change by strain amplitude enhancing. Besides, the strain changes the cyclic hardening/softening amount. Increasing the temperature caused an increase in the plastic strain amplitude of the specimen. According to Azadi and Shirazabad (2013), the temperature increase led to having the over-aging phenomenon in the material, which enhanced the plastic strain and decreased the strength.

The Ramberg-Osgood relation was used to investigate the cyclic behavior of the AlSi and the AlSi_N_HT6 samples so that the details could be seen in Table 2. There were differences between the cyclic behavior of AlSi at $250^{\circ} \mathrm{C}$ and also for AlSi_N_HT6 at $250^{\circ} \mathrm{C}$ and $300^{\circ} \mathrm{C}$. As the Ramberg-Osgood equation used experimental data of the mid-life cycle for evaluating the cyclic behavior and thus, there could be some differences between the cyclic behavior by the raw experimental results and the RambergOsgood equation. Material constants are represented in Table 3. As it can be seen in this table, by increasing the temperature, the average error and the maximum error gradually increased. One possible

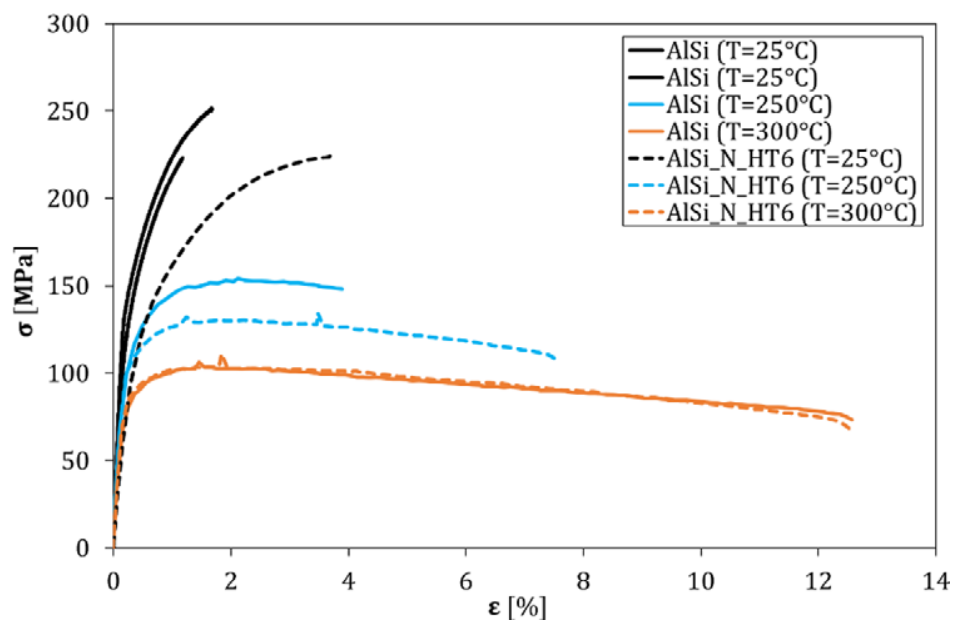

Figure 1. The uniaxial tensile test results for the AISi_N_HT6 and AISi specimens at various temperatures. 
(a)

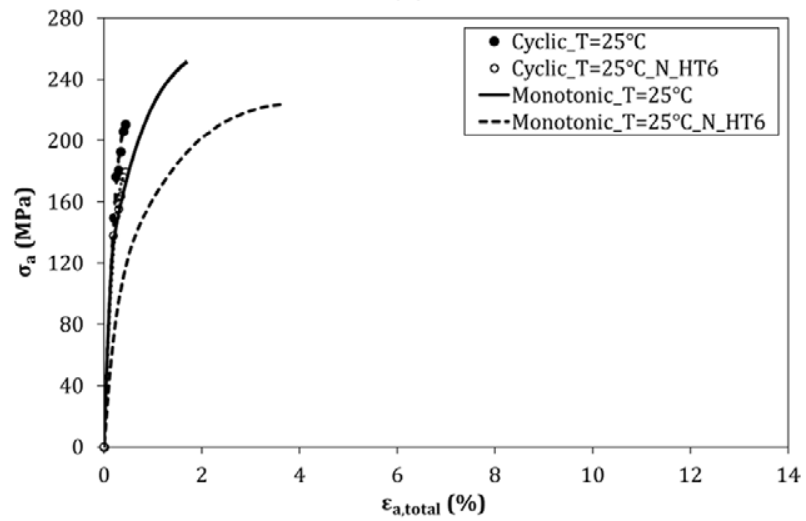

(b)

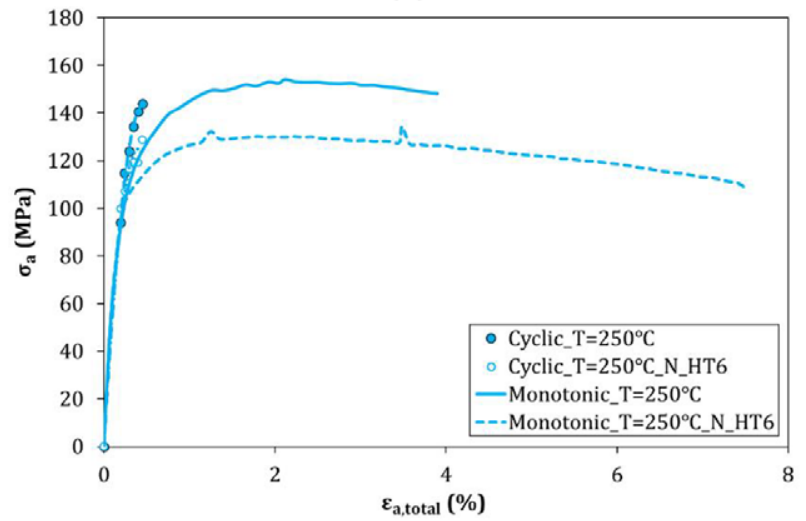

(c)

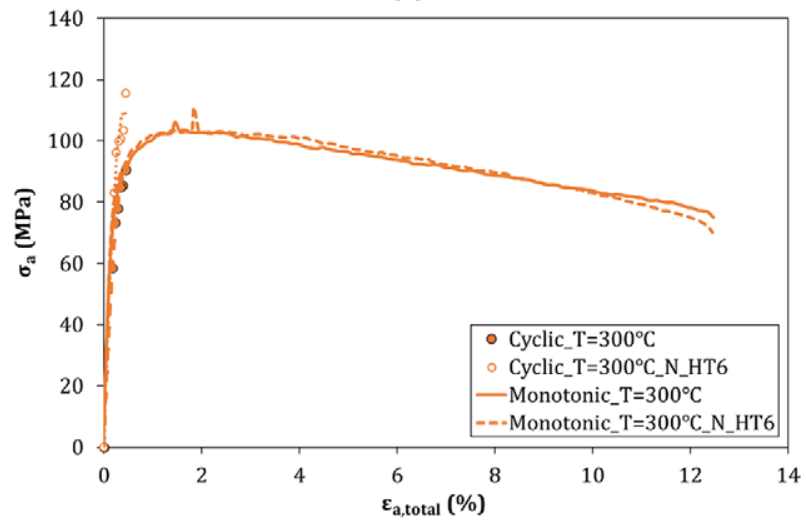

Figure 2. The Ramberg-Osgood relation for AISi_N_HT6 and AlSi at the temperature of (a) $25^{\circ} \mathrm{C}$, (b) $250^{\circ} \mathrm{C}$, and (c) $300^{\circ} \mathrm{C}$.

reason could be based on higher variations of fatigue testing data for standard samples, due to the microstructural changes under higher temperatures. However, the main concern for such changes in the relative error could be mentioned due to the scatter-band of experimental fatigue data.

The amount and the rate of cyclic hardening/softening for AlSi_N_HT6 and AlSi at various values of strain amplitudes and different temperatures are represented in Tables 4 and 5. Finally, the next step in this project is to model the cyclic behavior of the studied materials. Such this research was done by Felfeli 
Table 1. The ratio of the UTS to YS for both samples at various temperatures

\begin{tabular}{llll} 
& \multicolumn{2}{l}{ Temperature $\left({ }^{\circ} \mathrm{C}\right)$} & \\
\cline { 2 - 4 } Specimens & 25 & 250 & 300 \\
\hline AlSi & 2.23 & 1.54 & 1.29 \\
\hline AlSi_N_HT6 & 2.26 & 1.35 & 1.30 \\
\hline
\end{tabular}

(a)

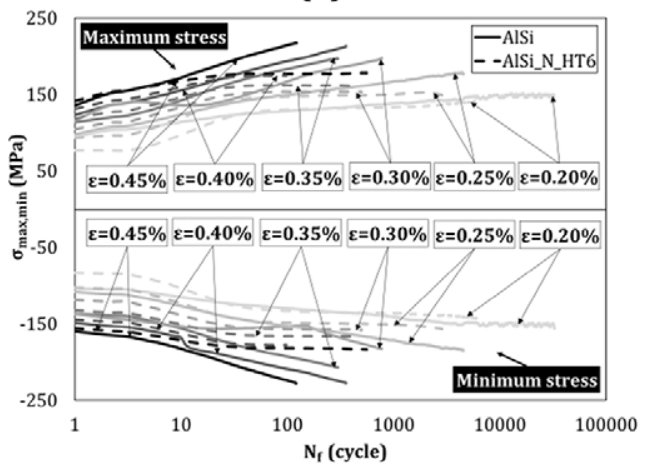

(c)

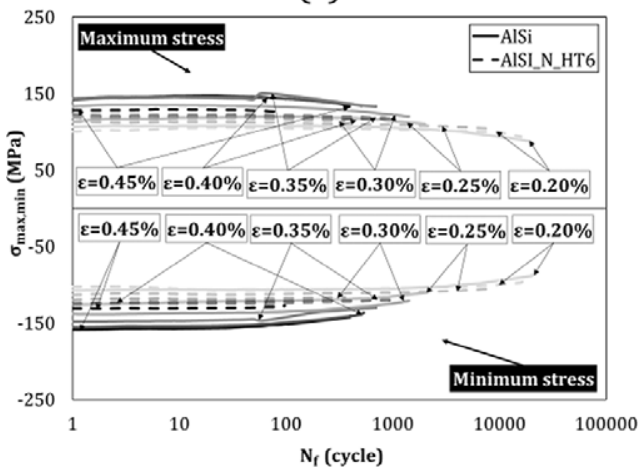

(b)

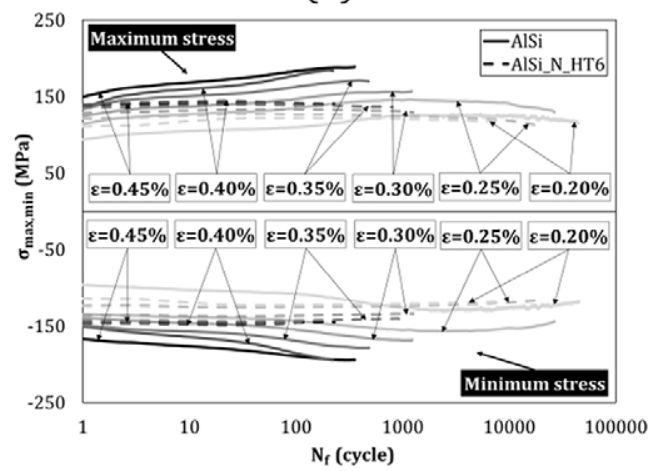

(d)

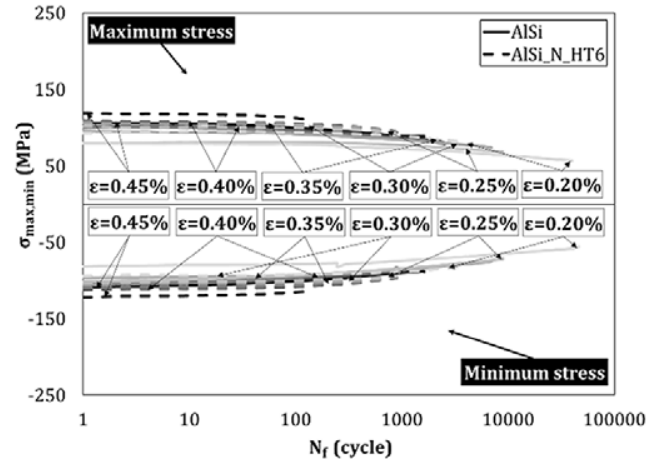

Figure 3. The maximum stress and the minimum stress during cycles for (a) AlSi at $25^{\circ} \mathrm{C}$, (b) AlSi_N_HT6 at $25^{\circ} \mathrm{C}$, (c) $\mathrm{AlSi}$ at $200^{\circ} \mathrm{C}$, (d) AlSi_N_HT6 at $200^{\circ} \mathrm{C}$, (e) AlSi at $250^{\circ} \mathrm{C}$, (f) AlSi_N_HT6 at $250^{\circ} \mathrm{C}$, (g) AlSi at $300^{\circ} \mathrm{C}$, and (h) AlSi_N_HT6 at $300^{\circ} \mathrm{C}$.

et al. (2015). They used four plasticity approaches to simulate stress-strain behaviors of aluminum alloys, at various strain rates (Felfeli et al., 2015).

\section{Discussion}

As seen, the stress increase during cycles occurred at room temperature, known as the cyclic hardening behavior for both AlSi_N_HT6 and AlSi. Moreover, the AlSi sample exhibited the cyclic hardening trend at $200^{\circ} \mathrm{C}$. However, at this temperature, cyclic softening was seen in AlSi_N_HT6. As reported in the literature (Fan et al., 2015), the cyclic hardening amount was lower at lower values of the strain amplitudes. For AlSi_N_HT6, this cyclic hardening was due to the effect of the stress transfer between the soft matrix and brittle particles (Luk et al., 2015). When the temperature changed to $250^{\circ} \mathrm{C}$ and $300^{\circ} \mathrm{C}$, the stress decreased during cycles. In other words, at high temperatures, the cyclic softening trend was 
(a)

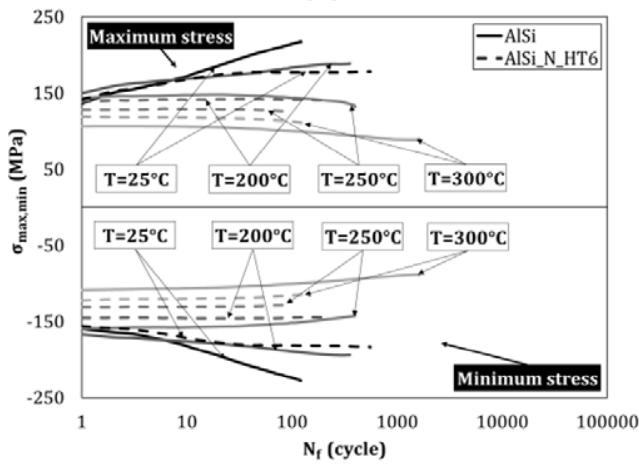

(c)

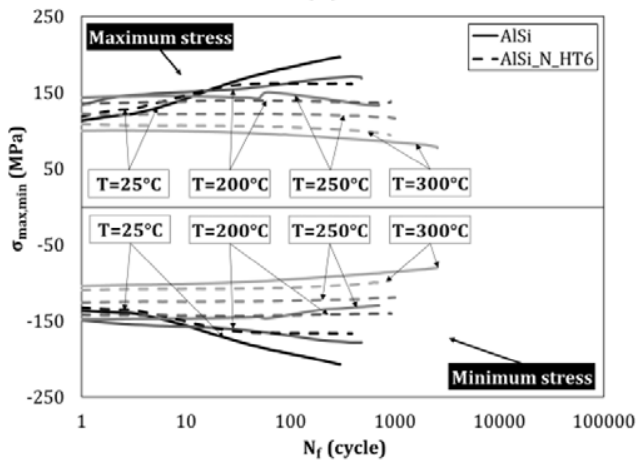

(e)

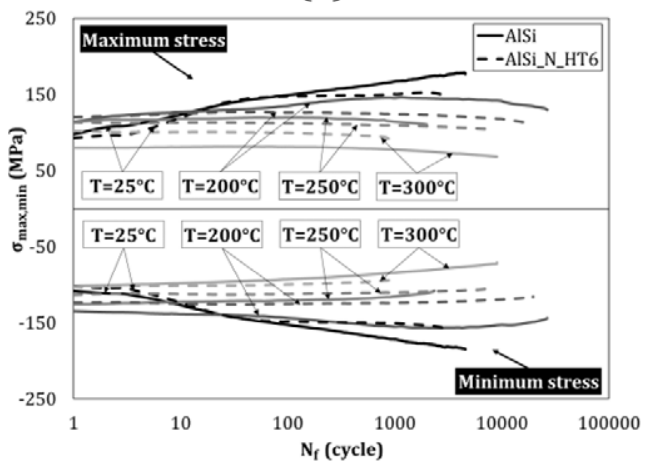

(b)

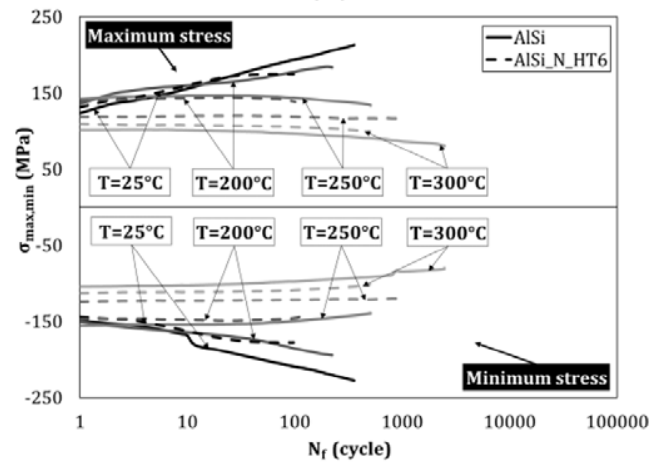

(d)

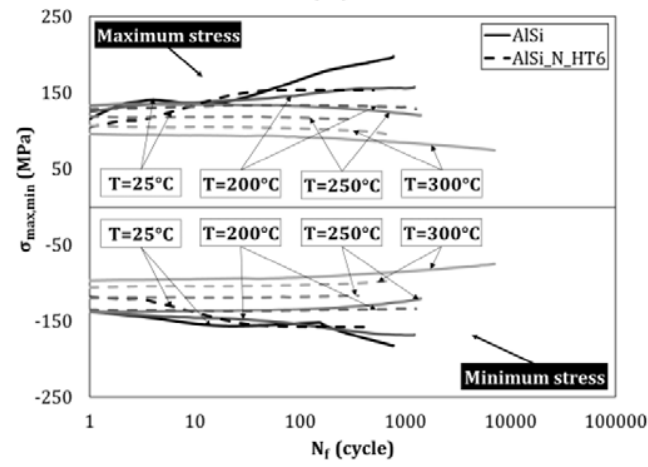

(f)

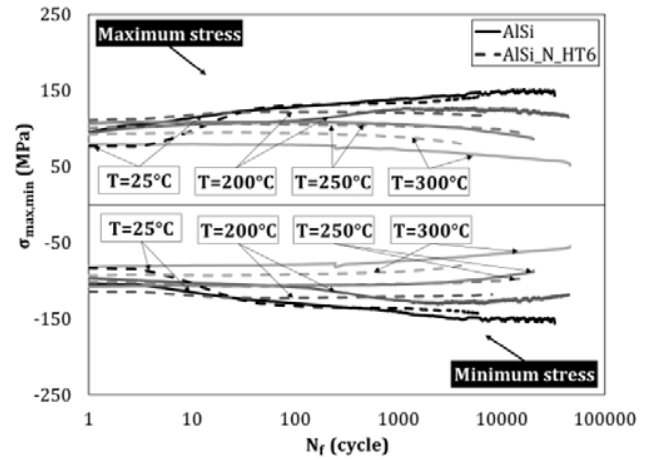

Figure 4. The maximum stress and the minimum stress during cycles under (a) $0.45 \%$ for AlSi, (b) $0.45 \%$ for AlSi_N_HT6, (c) $0.40 \%$ for AlSi, (d) $0.40 \%$ for AlSi_N_HT6, (e) $0.35 \%$ for AlSi, (f) $0.35 \%$ for AlSi_N_HT6, (g) $0.30 \%$ for AlSi, (h) 0.30 for AISi_N_HT6, (i) $0.25 \%$ for AlSi, (j) $0.25 \%$ for AISi_N_HT6, (k) $0.20 \%$ for AlSi, and (l) $0.20 \%$ for AlSi_N_HT6 of the total strain amplitude.

seen for both AlSi_N_HT6 and AlSi. For the base material, agreed results by Guo et al. (2017) were represented. The cyclic softening behavior in the material was affected by the temperature and also the strain amplitude (Liu et al., 2013).

As another comparison, AlSi_N_HT6 had higher plastic strains than that of the AlSi sample, which is due to the heat-treating process (Azadi \& Shirazabad, 2013). As another reason, the plasticity of the base metal was increased by the reinforcing phase. As reported by Luk et al. (2015), the reason for the AlSi_N_HT6 cyclic hardening trend could be the stress transfer, which would be occurred between the soft aluminum matrix and brittle nano-particles. 
(a)

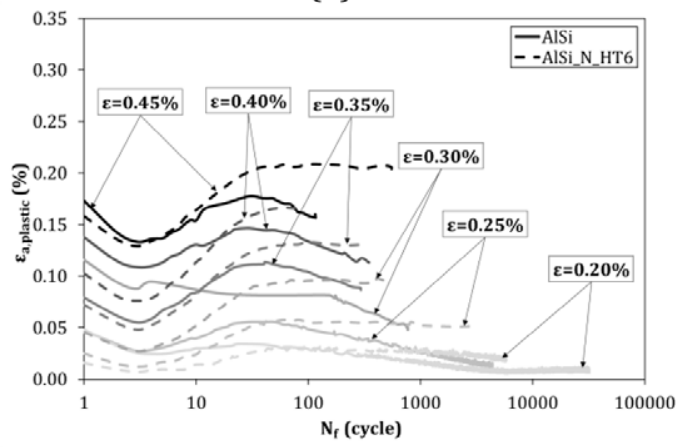

(c)

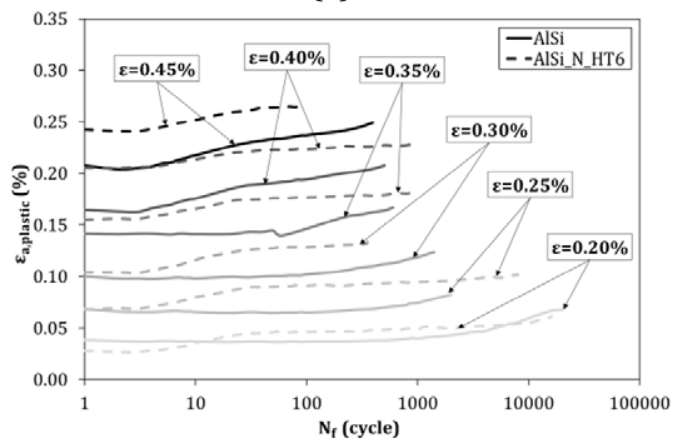

(b)

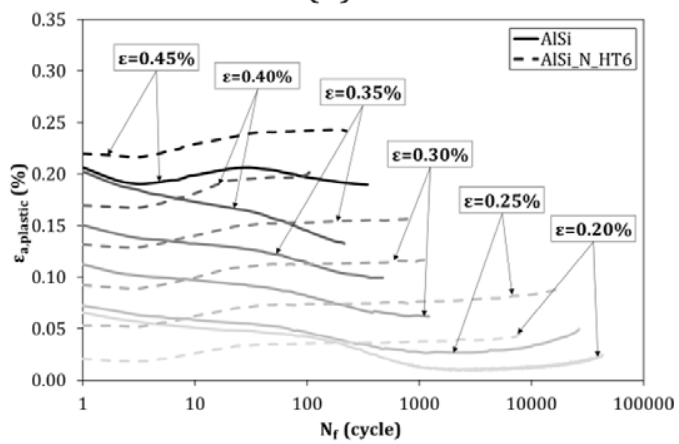

(d)

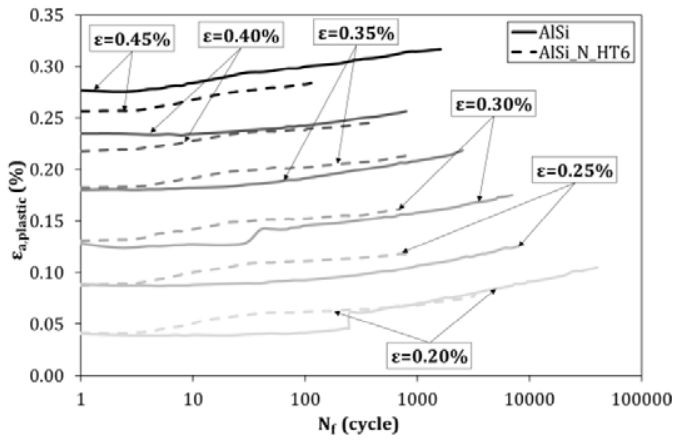

Figure 5. The amplitude of the plastic strain during cycles at the temperature of (a) $25^{\circ} \mathrm{C}$ for AlSi, (b) $25^{\circ} \mathrm{C}$ for AISi_N_HT6, (c) $200^{\circ} \mathrm{C}$ for AlSi, (d) $200^{\circ} \mathrm{C}$ for AlSi_N_HT6, (e) $250^{\circ} \mathrm{C}$ for AlSi, (f) $250^{\circ} \mathrm{C}$ for AlSi_N_HT6, (g) $300^{\circ} \mathrm{C}$ for AlSi, and (h) $300^{\circ} \mathrm{C}$ for AlSi_N_HT6.

\section{Conclusions}

Highlighted experimental results in this research are as follows:

- The temperature had more effects than that of the total strain amplitude on cyclic behaviors.

- As the strain amplitude decreased, the rate of cyclic hardening/softening also decreased.

- The amount of the cyclic hardening trend at $25^{\circ} \mathrm{C}$ was higher than that of its trend at $200^{\circ} \mathrm{C}$.

- Increasing the temperature led to a decrease in the amount of cyclic hardening. In other words, increasing the temperature caused to increase in the amount of cyclic softening

- The rate of cyclic hardening decreased and the rate of cyclic softening increased by an increase in the temperature.

For further investigations, describing precipitates in the material microstructure will be studied under various strains and temperatures of fatigue testing. Moreover, material science should be generally considered for describing the differences in LCF lifetimes between two different materials. By presenting such a description, the reinforcing role of nano-particles could be found in the base material. This job will be presented by authors in the other researches, besides this data-in-brief article. 
(a)

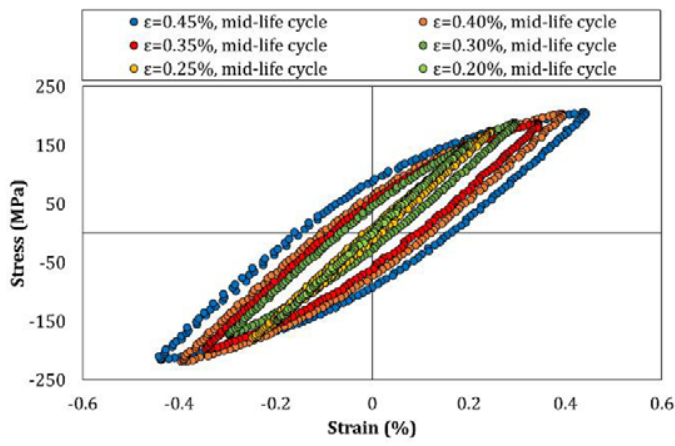

(c)

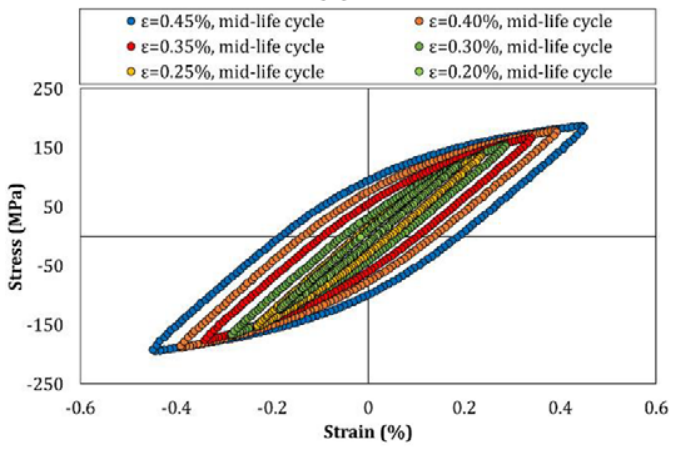

(e)

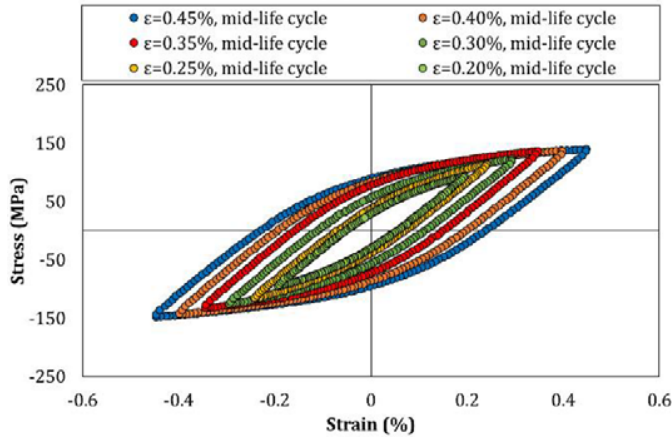

(g)

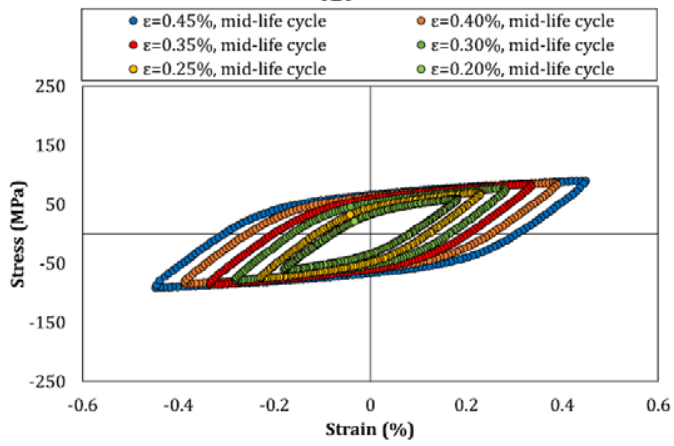

(b)

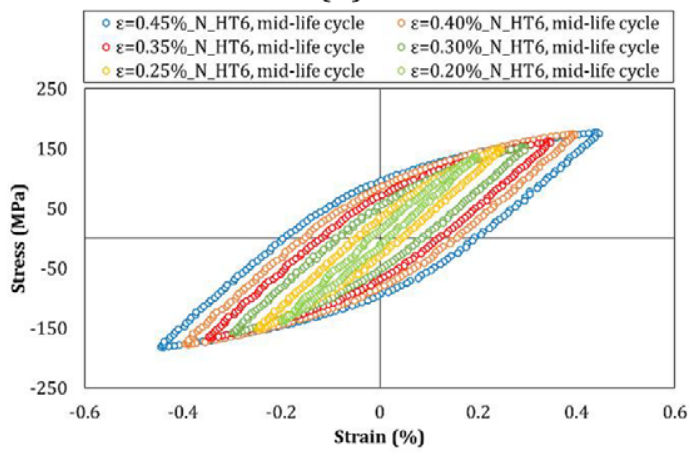

(d)

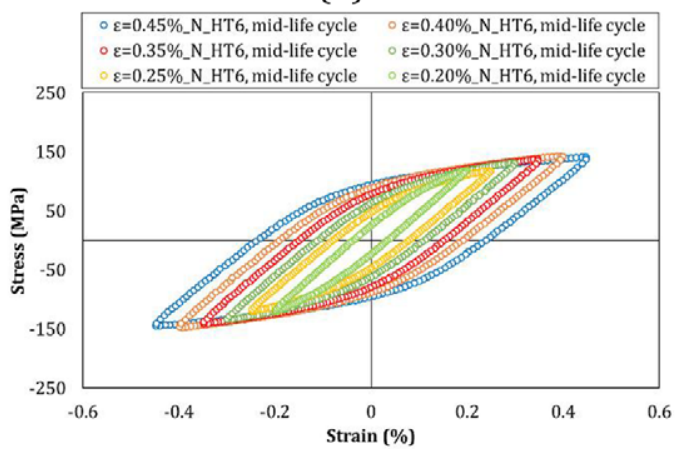

(f)

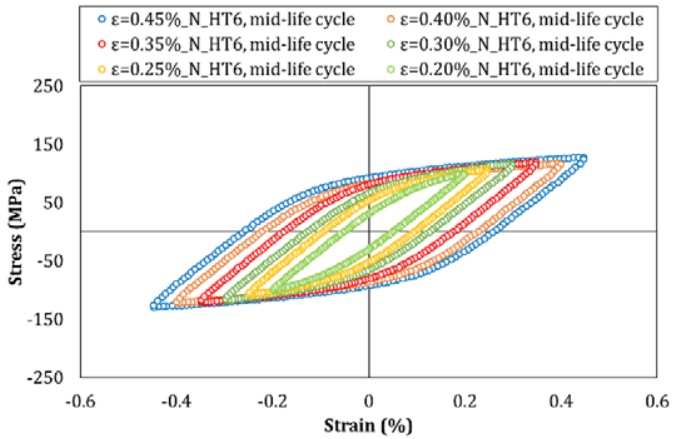

(h)

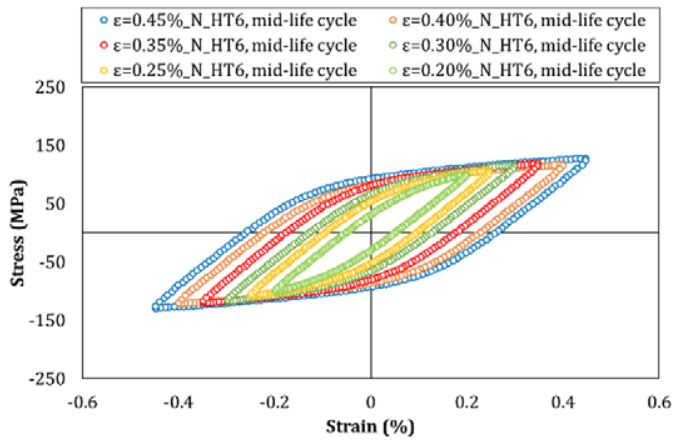

Figure 6. The effect of the total strain amplitude on the hysteresis loop at the temperature of (a) $25^{\circ} \mathrm{C}$ for AlSi, (b) $25^{\circ} \mathrm{C}$ for AlSi_N_HT6, (c) $200^{\circ} \mathrm{C}$ for AlSi, (d) $200^{\circ} \mathrm{C}$ for AlSi_N_HT6, (e) $250^{\circ} \mathrm{C}$ for AlSi, (f) $250^{\circ} \mathrm{C}$ for AlSi_N_HT6, (g) $300^{\circ} \mathrm{C}$ for AlSi, and (h) $300^{\circ} \mathrm{C}$ for AlSi_N_HT6. 
(a)

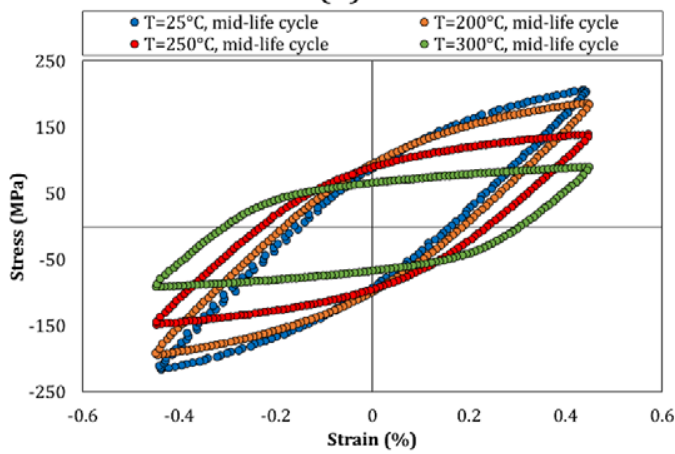

(c)

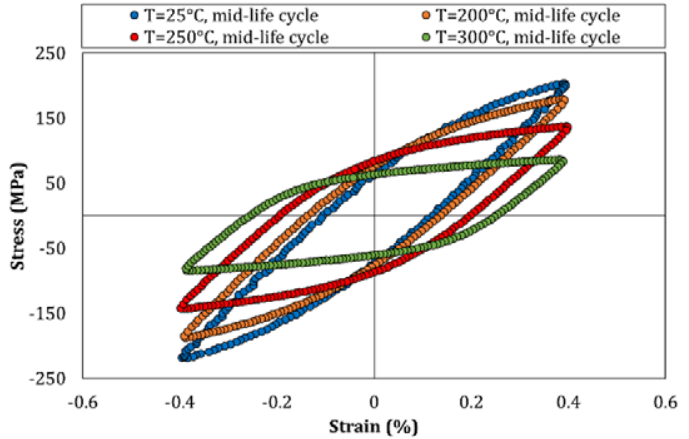

(e)

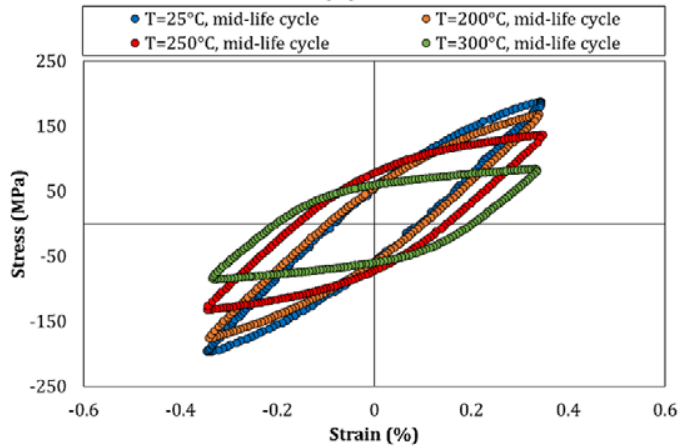

(g)

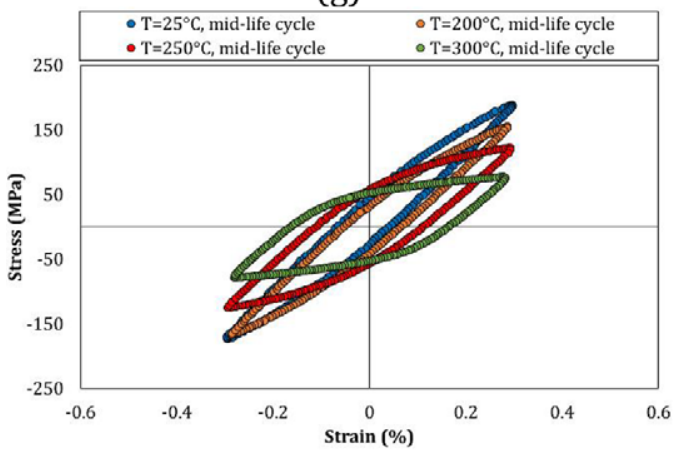

(i) (b)

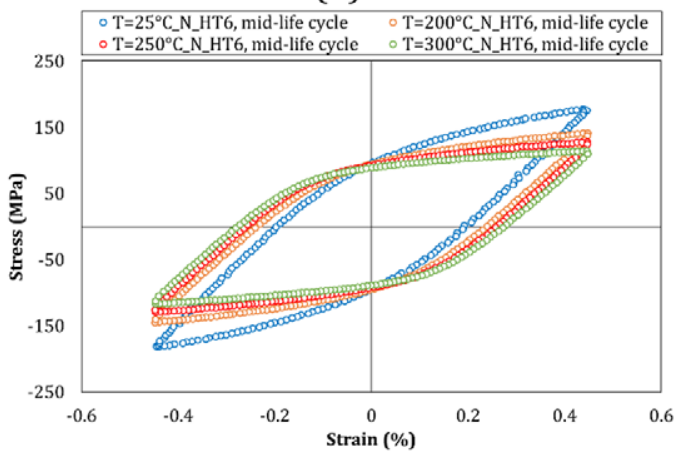

(d)

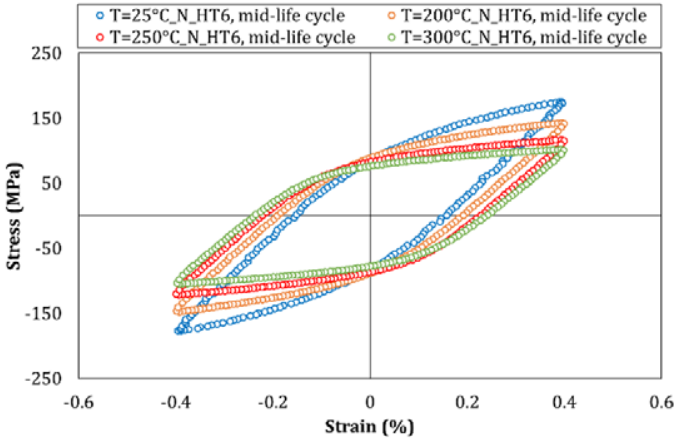

(f)

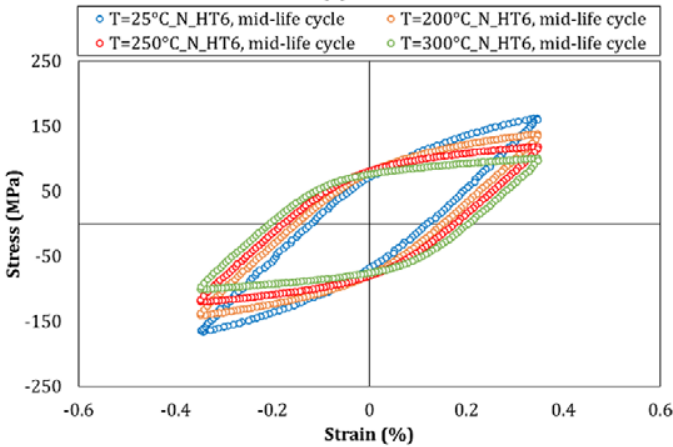

(h)

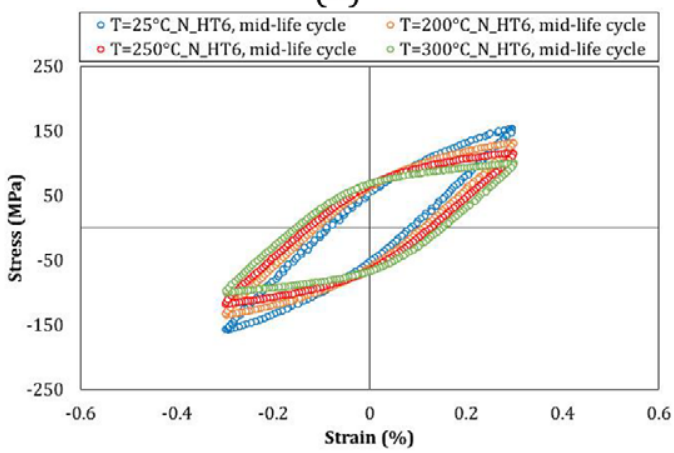

(j)

Figure 7. The temperature effect on the hysteresis loop under the strain amplitude of (a) $0.45 \%$ for AlSi, (b) $0.45 \%$ for AlSi_N_HT6, (c) $0.40 \%$ for AlSi, (d) $0.40 \%$ for AlSi_N_HT6, (e) $0.35 \%$ for AlSi, (f) $0.35 \%$ for AlSi_N_HT6, (g) $0.30 \%$ for AlSi, (h) $0.30 \%$ for AISi_N_HT6, (i) $0.25 \%$ for AISi, (j) $0.25 \%$ for AISi_N_HT6, (k) $0.20 \%$ for AISi, and (l) $0.20 \%$ for AlSi_N_HT6. 
Mohammad Azadi et al.

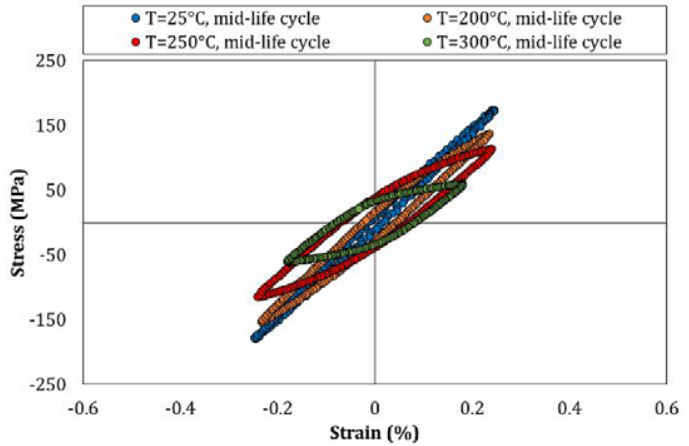

(k)

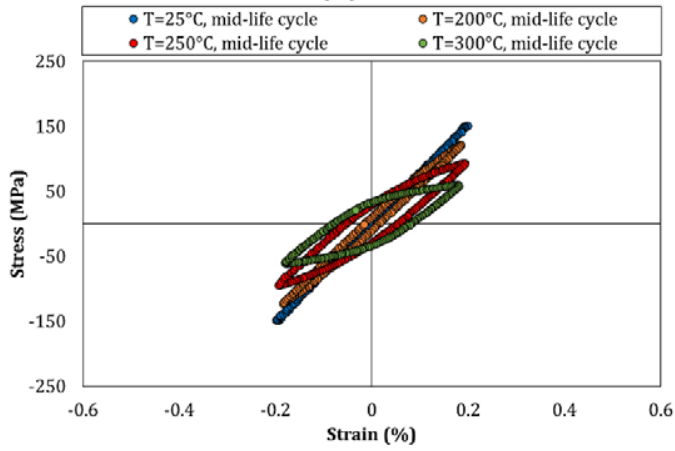

Figure 7. (cont.)

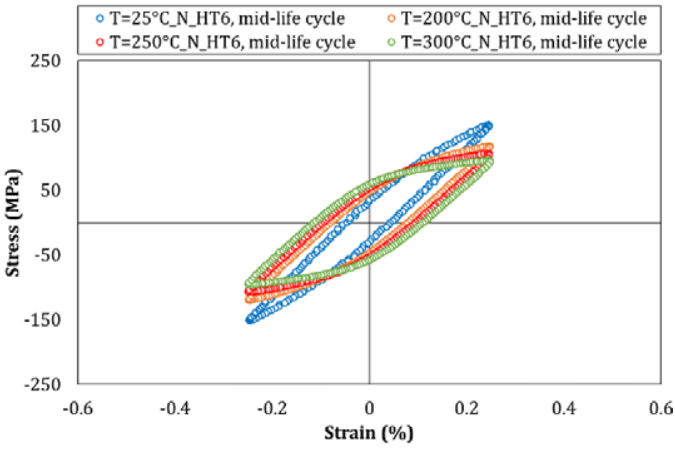

(1)

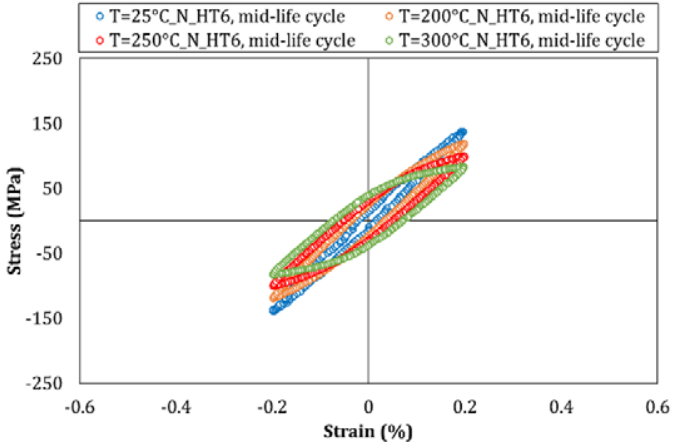


(a)

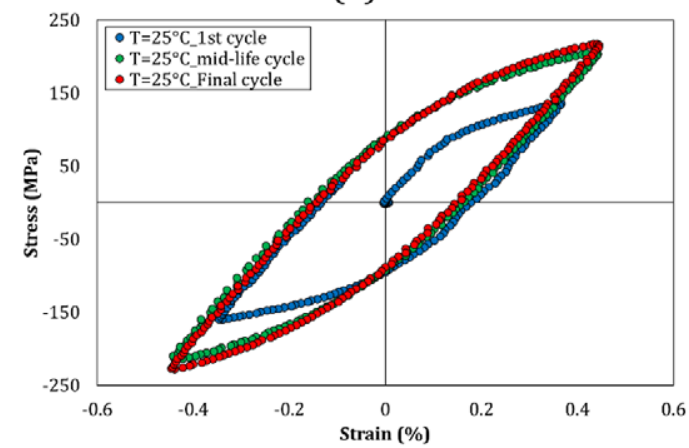

(c)

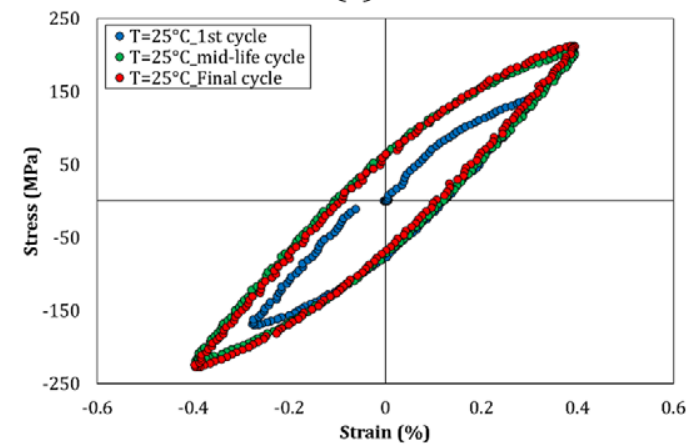

(e)

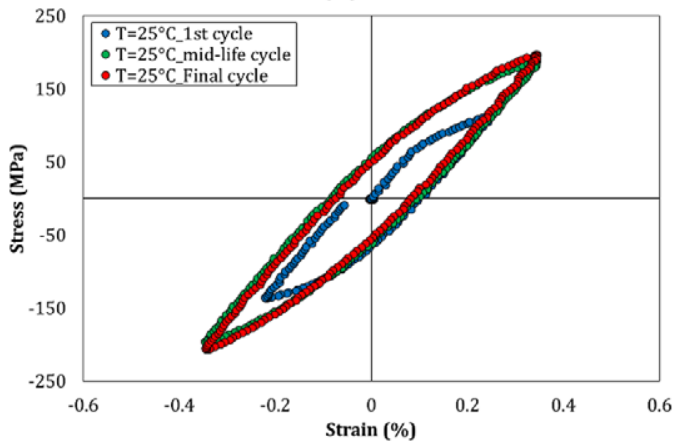

(g)

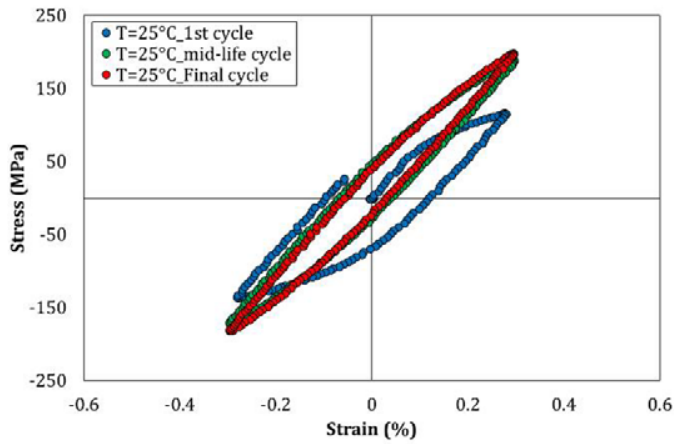

(i) (b)

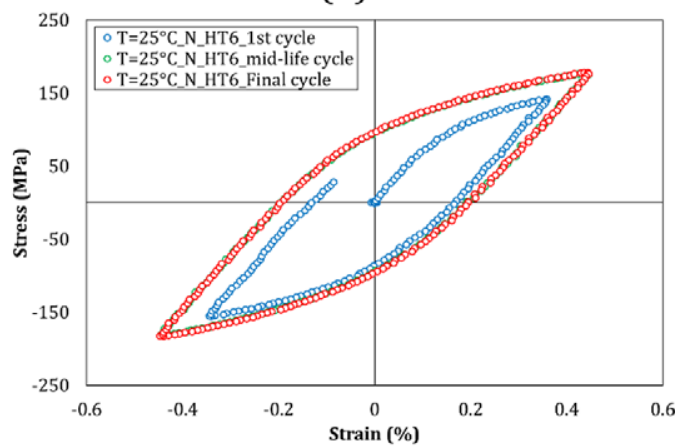

(d)

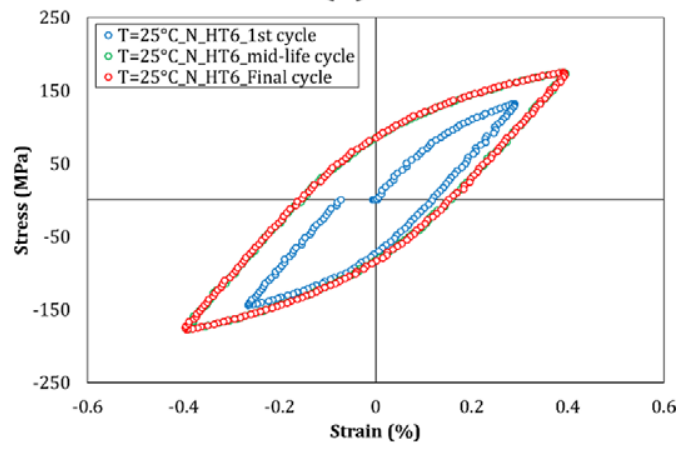

(f)

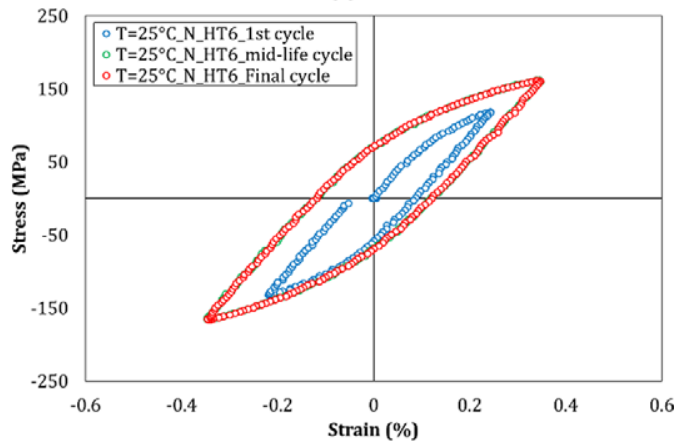

(h)

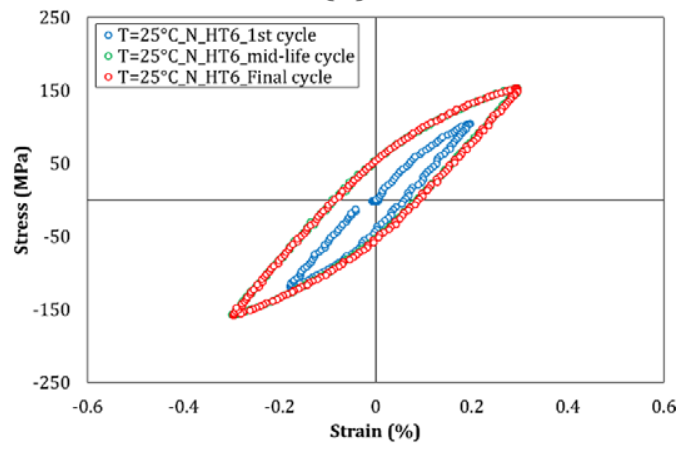

(j)

Figure 8. The stress-strain hysteresis for the first cycle, the mid-life cycle and the final cycle at $25^{\circ} \mathrm{C}$ and at the strain amplitude of (a) $0.45 \%$ for AISi, (b) $0.45 \%$ for AISi_N_HT6, (c) $0.40 \%$ for AlSi, (d) $0.40 \%$ for AlSi_N_HT6, (e) $0.35 \%$ for AlSi, (f) $0.35 \%$ for AlSi_N_HT6, (g) $0.30 \%$ for AISi, (h) $0.30 \%$ for AlSi_N_HT6, (i) $0.25 \%$ for AlSi, (j) $0.25 \%$ for AlSi_N_HT6, (k) $0.20 \%$ for AlSi, and (l) $0.20 \%$ for AlSi_N_HT6. 
12 Mohammad Azadi et al.

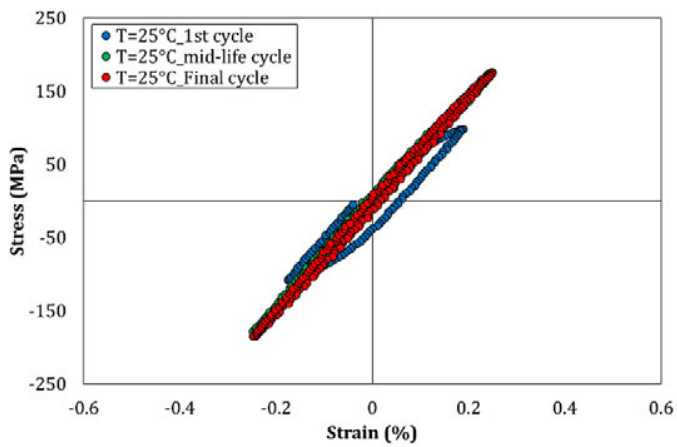

(k)

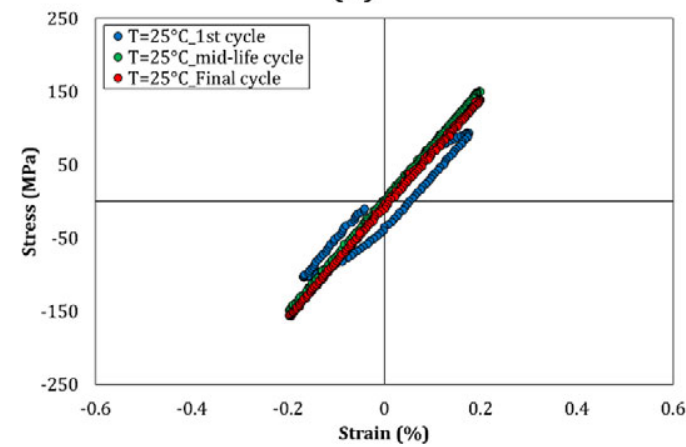

Figure 8. (cont.)

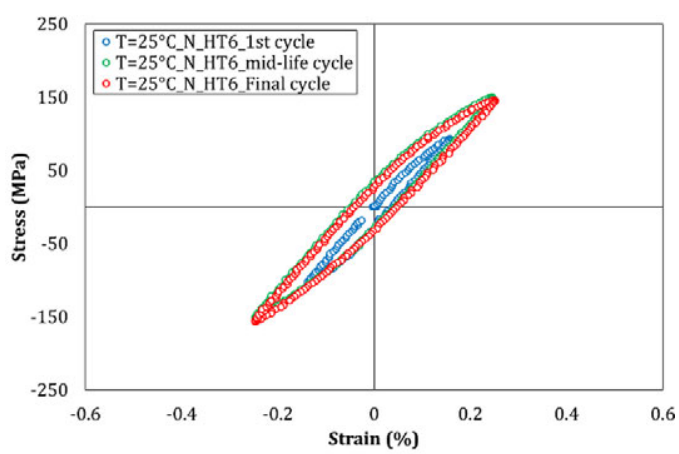

(l)

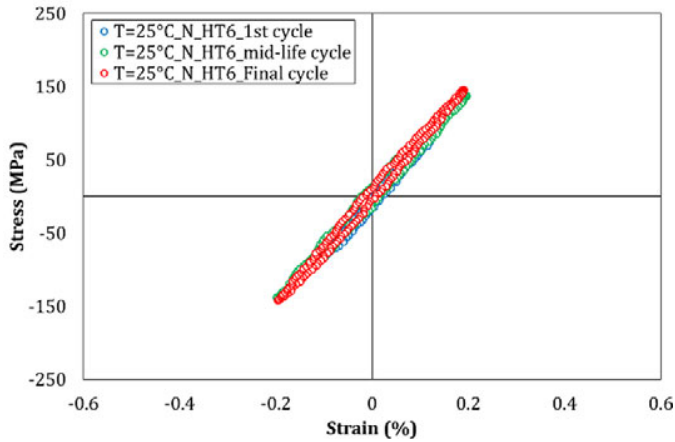


(a)

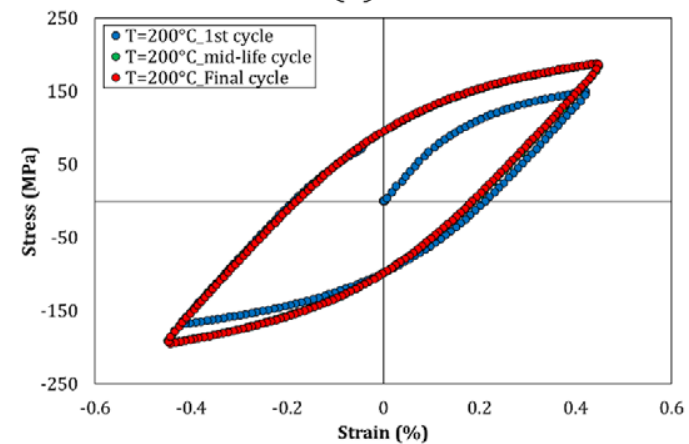

(c)

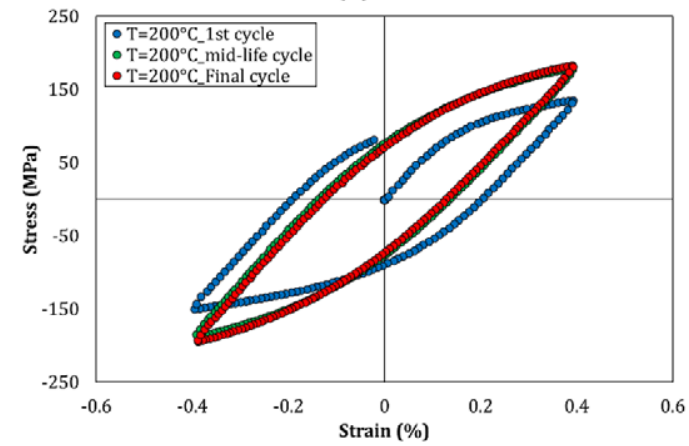

(e)

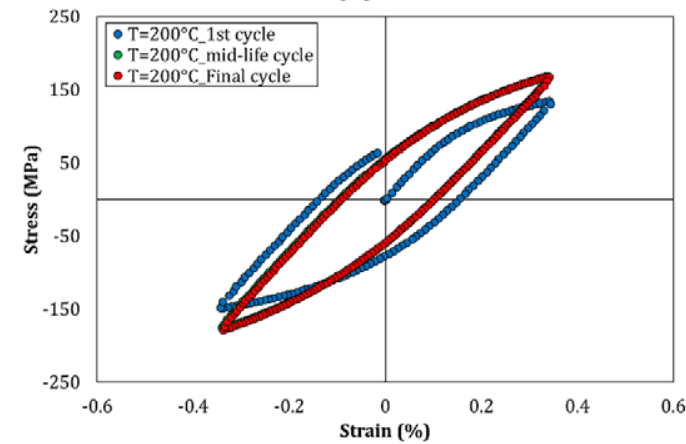

(g)

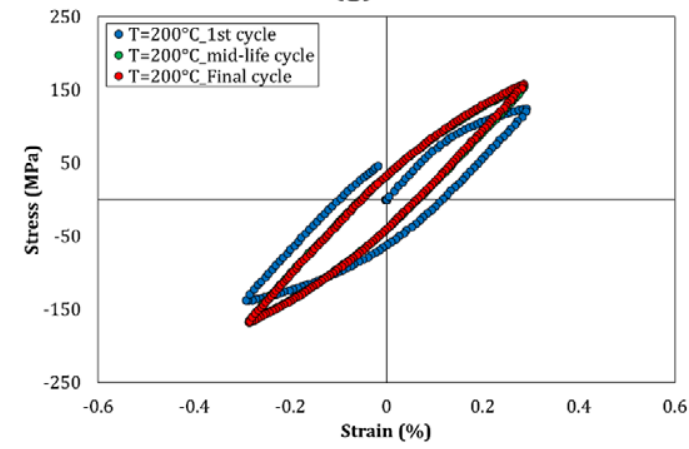

(i) (b)

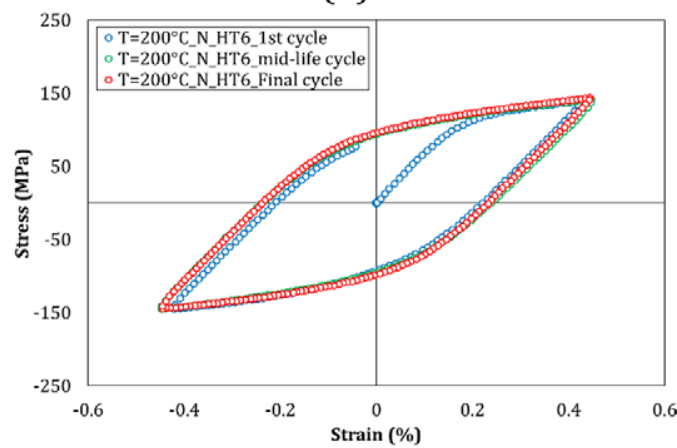

(d)

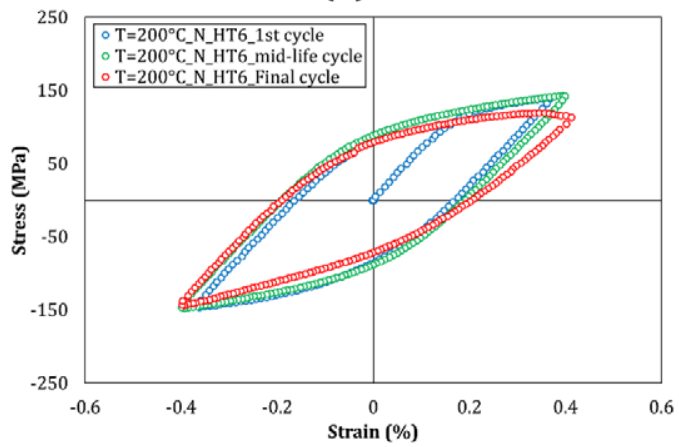

(f)

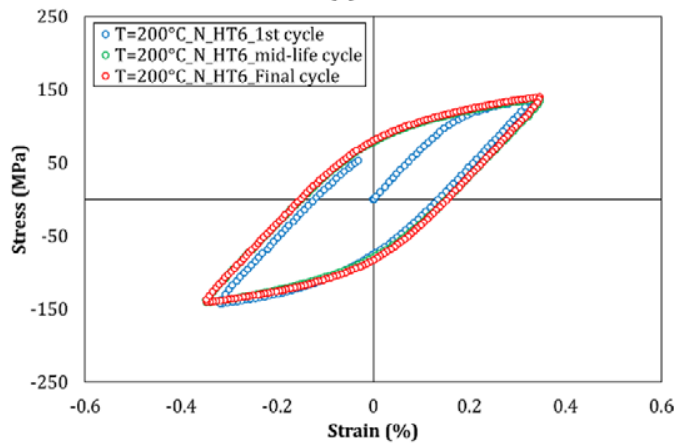

(h)

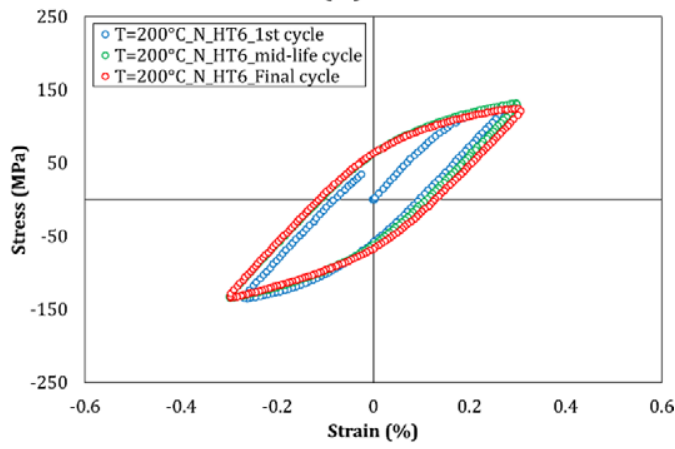

(j)

Figure 9. The stress-strain hysteresis for the first cycle, the mid-life cycle and the final cycle at $200^{\circ} \mathrm{C}$ and at the strain amplitude of (a) $0.45 \%$ for AISi, (b) $0.45 \%$ for AISi_N_HT6, (c) 0.40\% for AlSi, (d) 0.40\% for AlSi_N_HT6, (e) 0.35\% for AlSi, (f) $0.35 \%$ for AISi_N_HT6, (g) $0.30 \%$ for AlSi, (h) $0.30 \%$ for AISi_N_HT6, (i) $0.25 \%$ for AlSi, (j) $0.25 \%$ for AlSi_N_HT6, (k) $0.20 \%$ for AlSi, and (I) $0.20 \%$ for AlSi_N_HT6. 
14 Mohammad Azadi et al.

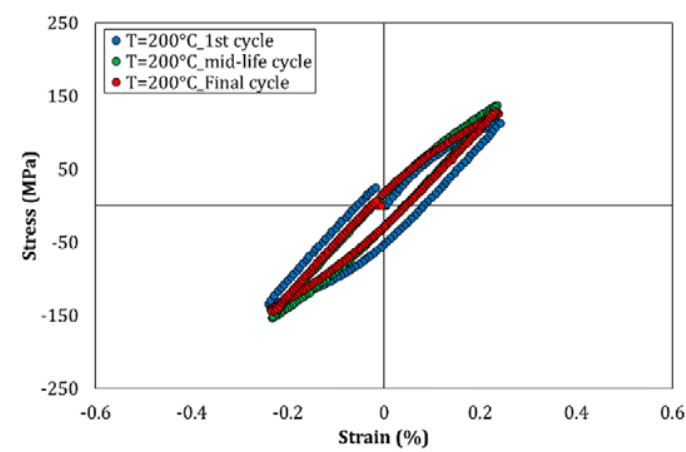

(k)

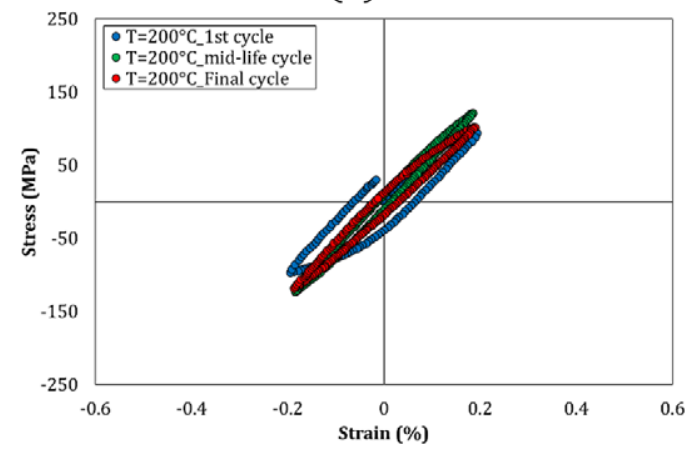

Figure 9. (cont.)

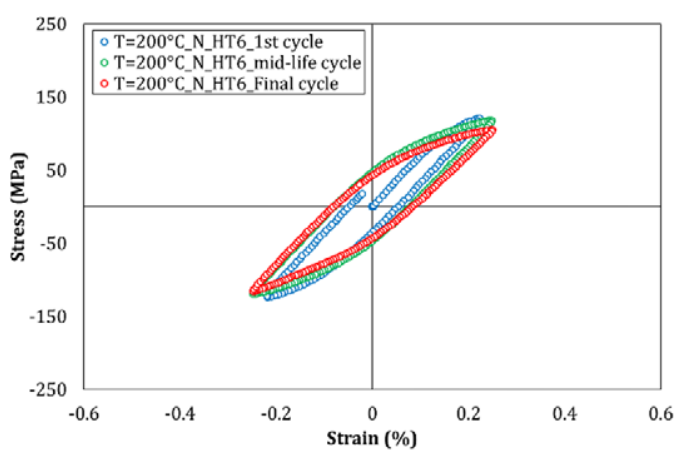

(l)

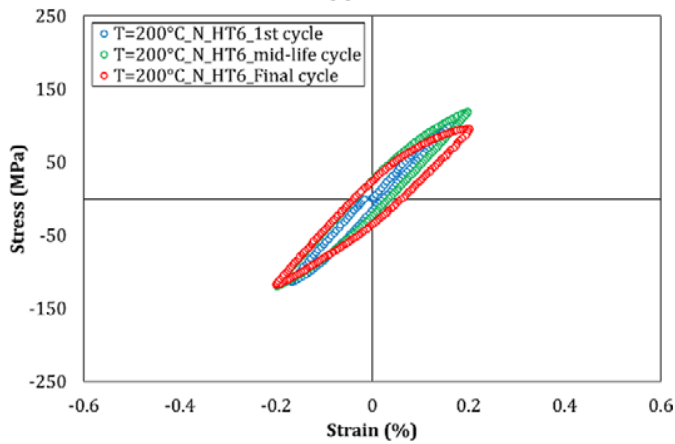


(a)

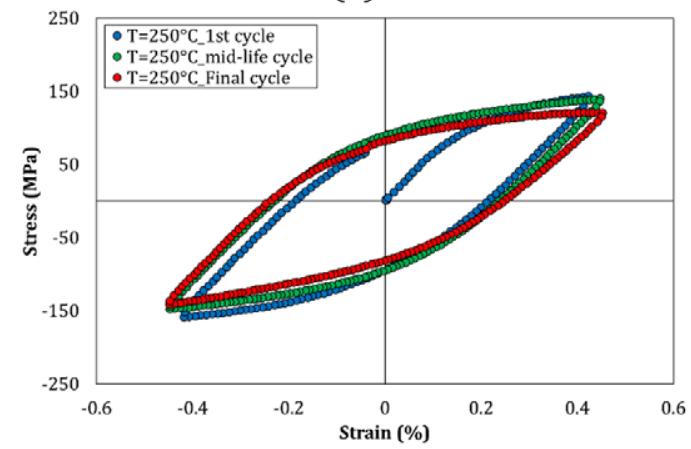

(c)

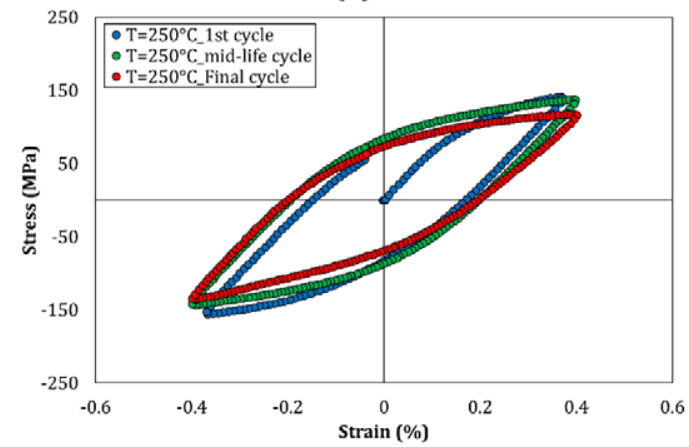

(e)

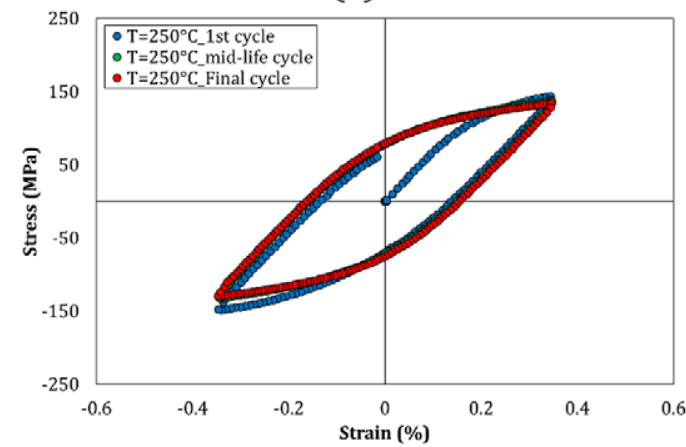

(g)

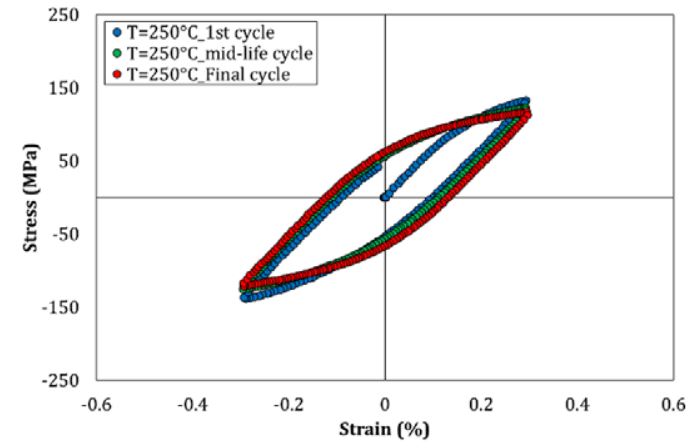

(i) (b)

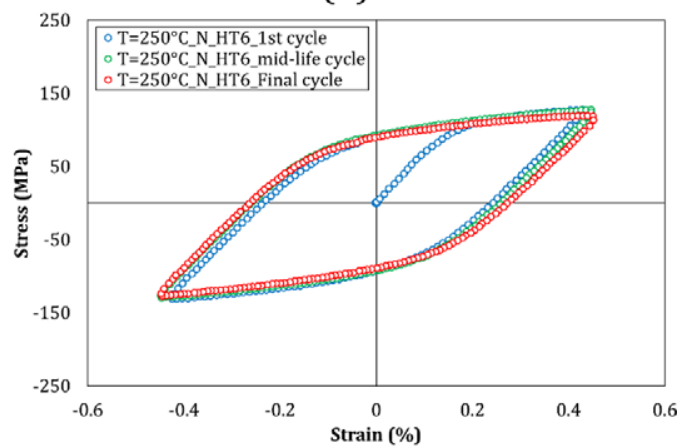

(d)

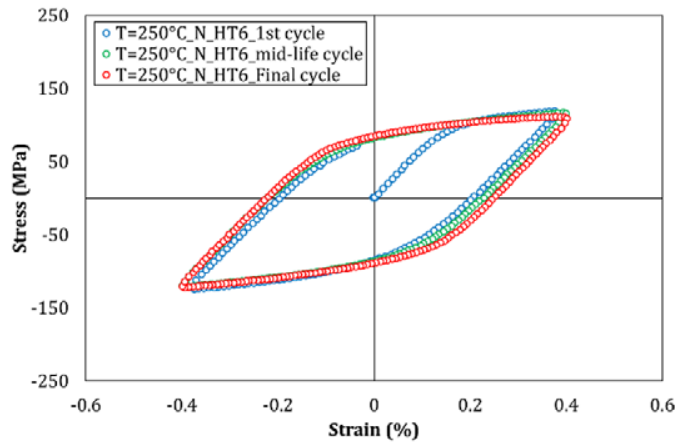

(f)

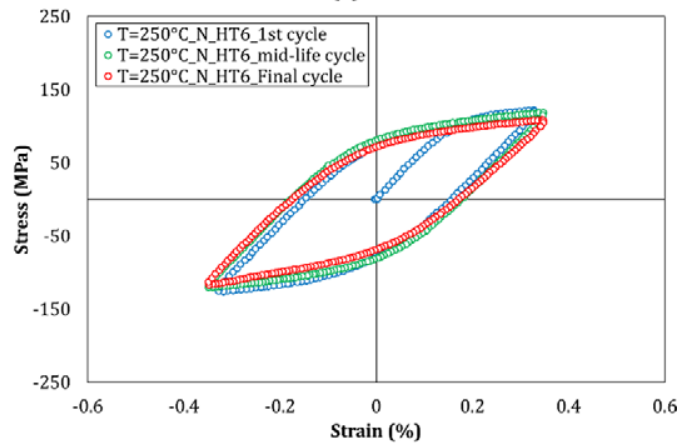

(h)

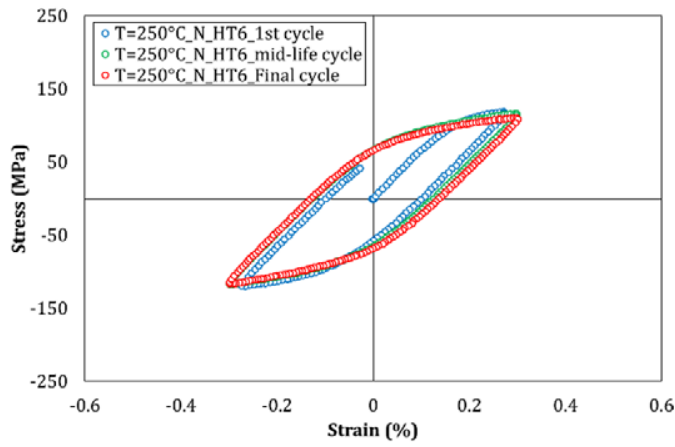

(j)

Figure 10. The stress-strain hysteresis for the first cycle, the mid-life cycle and the final cycle at $250^{\circ} \mathrm{C}$ and at the strain amplitude of (a) $0.45 \%$ for AlSi, (b) $0.45 \%$ for AlSi_N_HT6, (c) $0.40 \%$ for AlSi, (d) $0.40 \%$ for AlSi_N_HT6, (e) $0.35 \%$ for AlSi, (f) $0.35 \%$ for AlSi_N_HT6, (g) $0.30 \%$ for AlSi, (h) $0.30 \%$ for AlSi_N_HT6, (i) $0.25 \%$ for AlSi, (j) $0.25 \%$ for AlSi_N_HT6, (k) $0.20 \%$ for AlSi, and (l) $0.20 \%$ for AlSi_N_HT6. 
16 Mohammad Azadi et al.

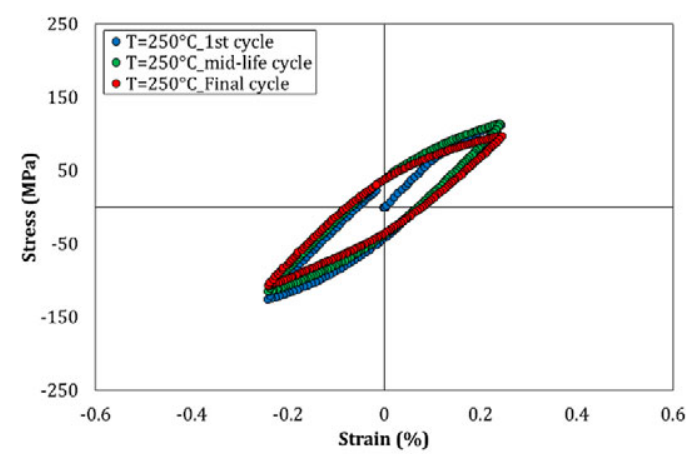

(k)

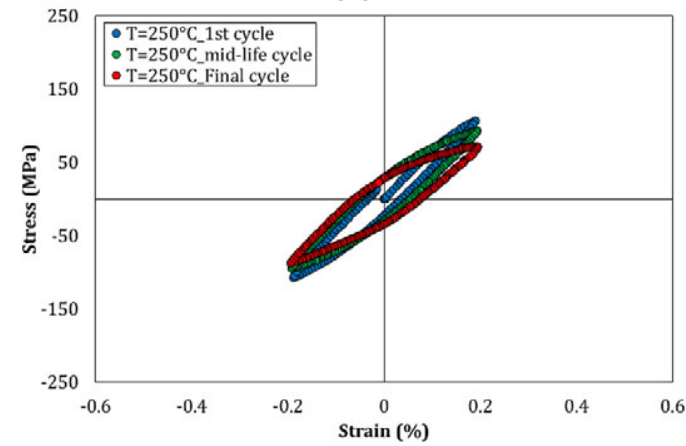

Figure 10. (cont.)

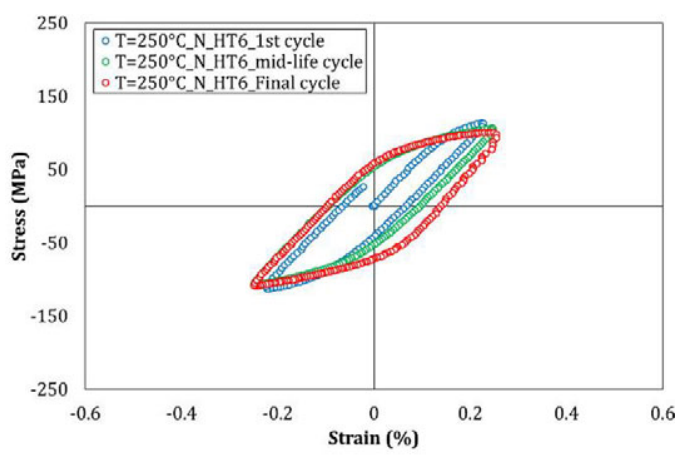

(l)

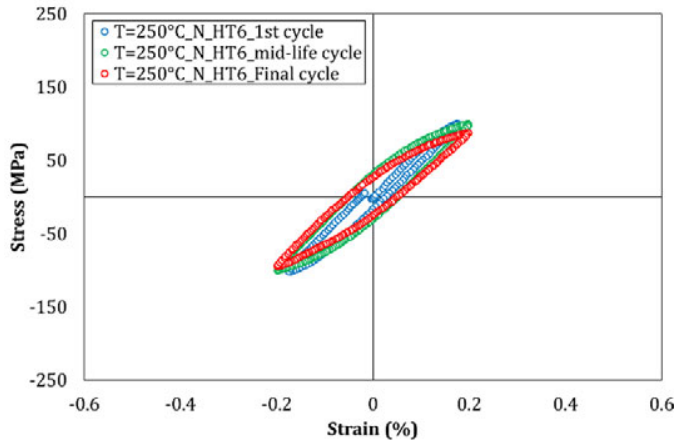


(a)

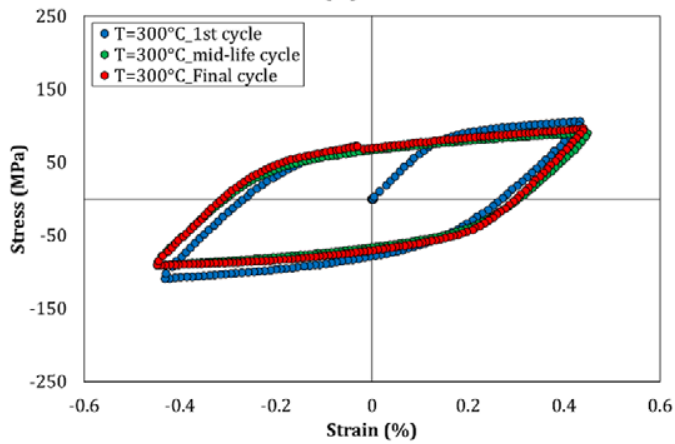

(c)

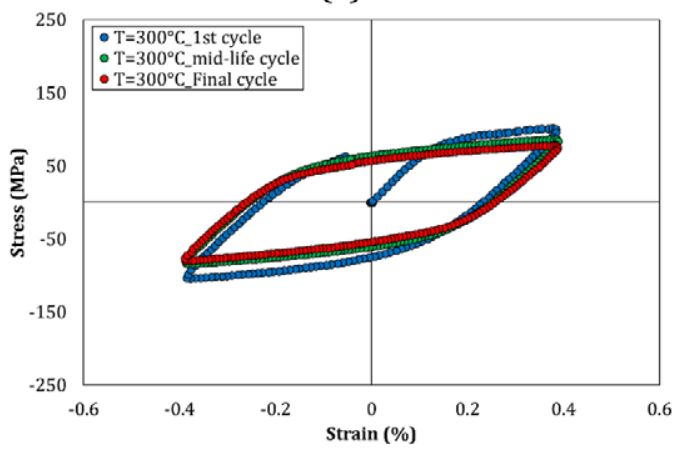

(e)

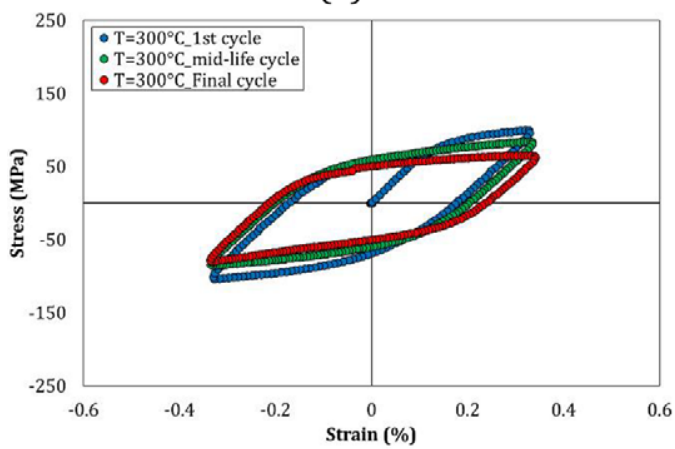

(g)

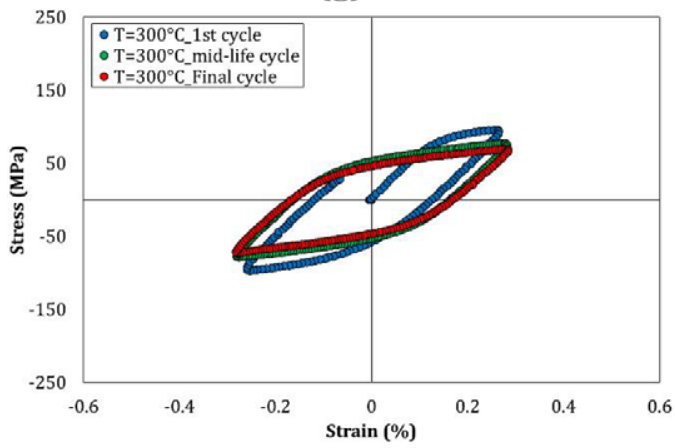

(i) (b)

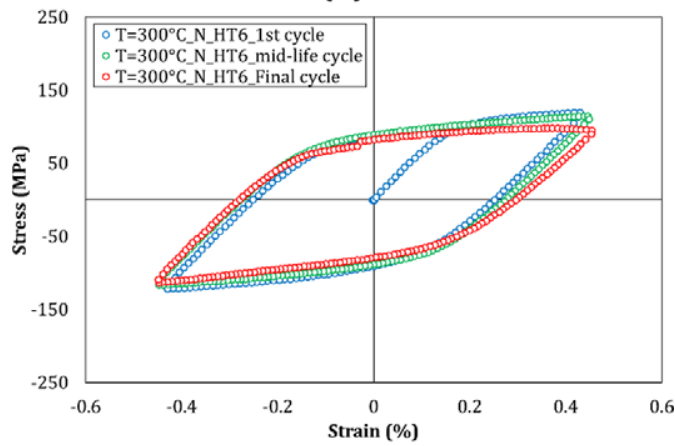

(d)

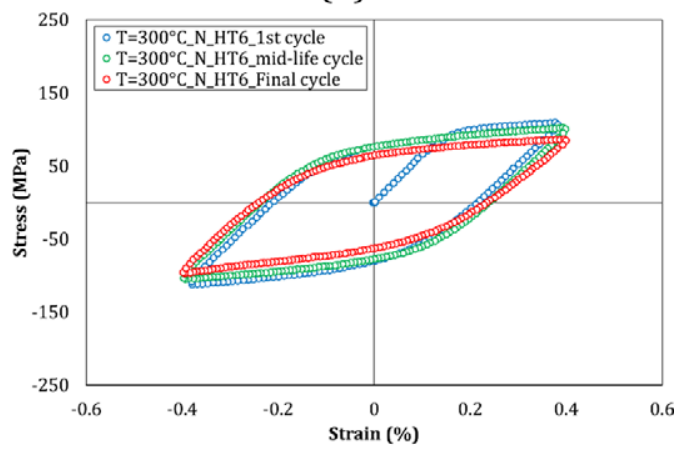

(f)

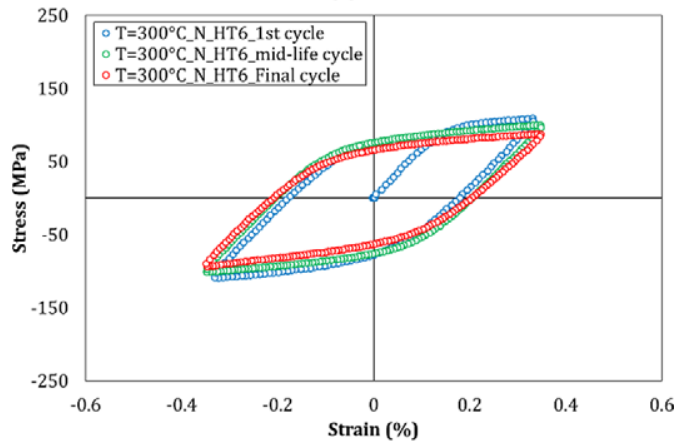

(h)

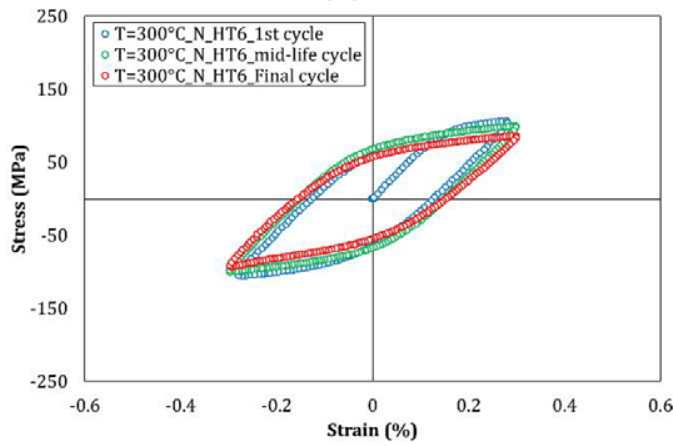

(j)

Figure 11. The stress-strain hysteresis for the first cycle, the mid-life cycle and the final cycle at $300^{\circ} \mathrm{C}$ and at the strain amplitude of (a) $0.45 \%$ for AlSi, (b) $0.45 \%$ for AISi_N_HT6, (c) $0.40 \%$ for AlSi, (d) $0.40 \%$ for AlSi_N_HT6, (e) $0.35 \%$ for AlSi, (f) $0.35 \%$ for AlSi_N_HT6, (g) $0.30 \%$ for AlSi, (h) $0.30 \%$ for AlSi_N_HT6, (i) $0.25 \%$ for AlSi, (j) $0.25 \%$ for AlSi_N_HT6, (k) $0.20 \%$ for AlSi, and (l) $0.20 \%$ for AlSi_N_HT6. 
18 Mohammad Azadi et al.

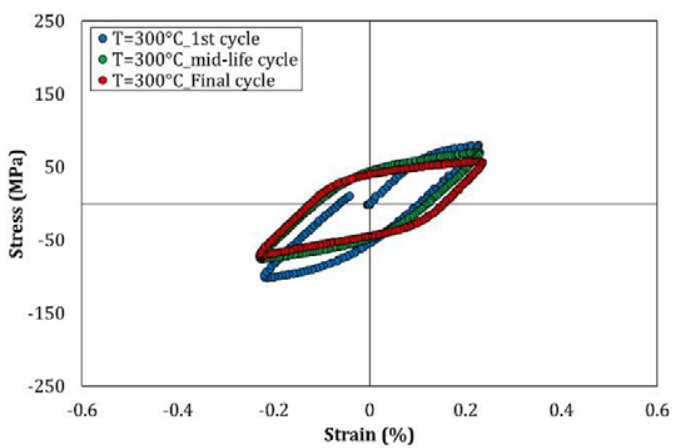

(k)

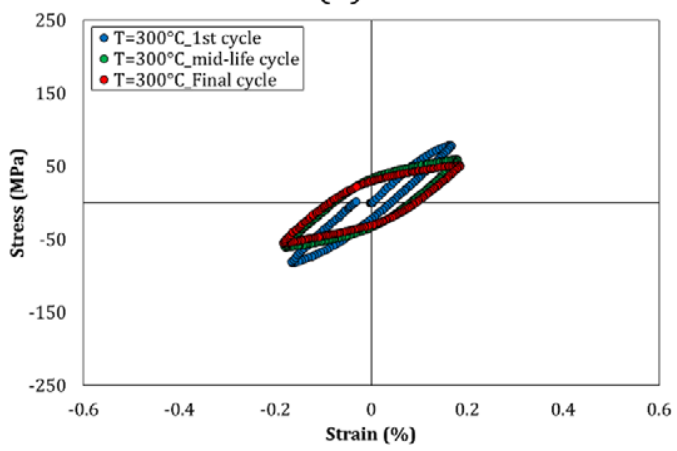

Figure 11. (cont.)

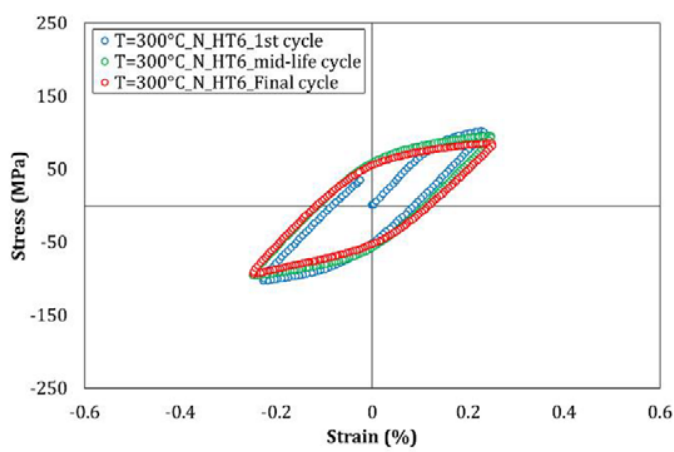

(l)

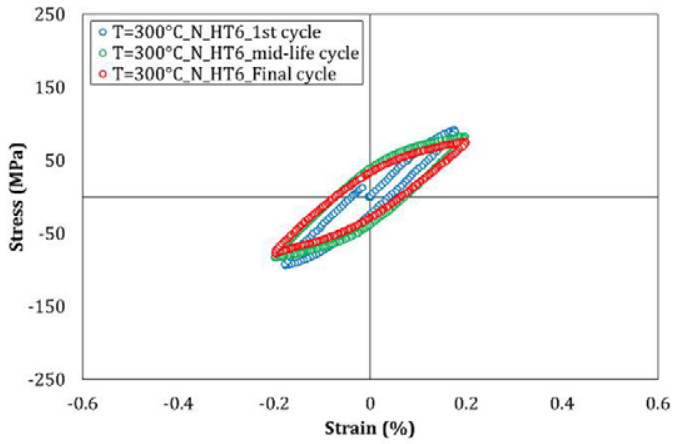


(a)

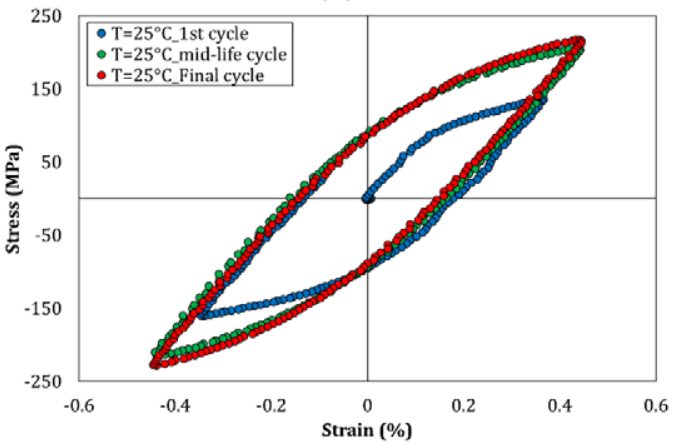

(c)

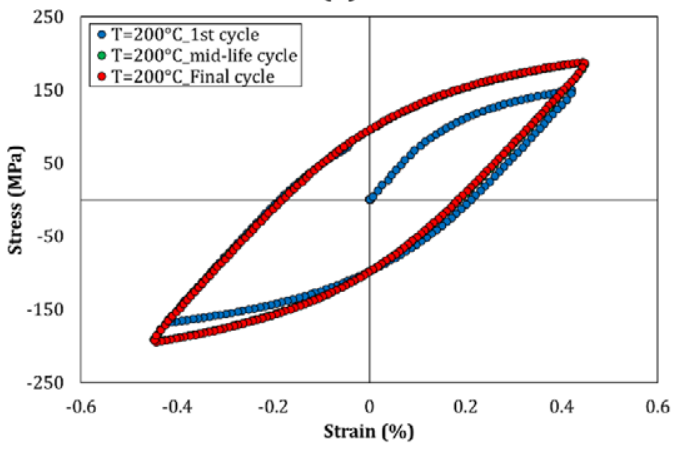

(e)

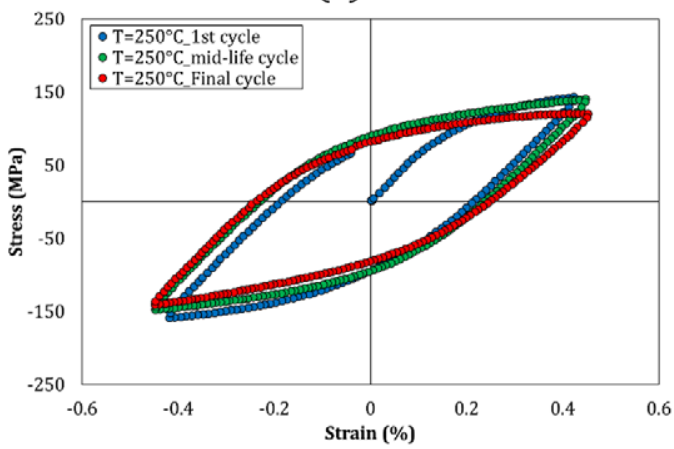

(g)

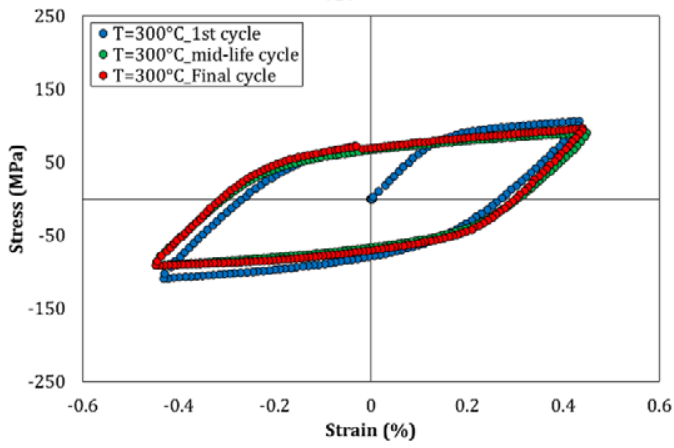

(b)

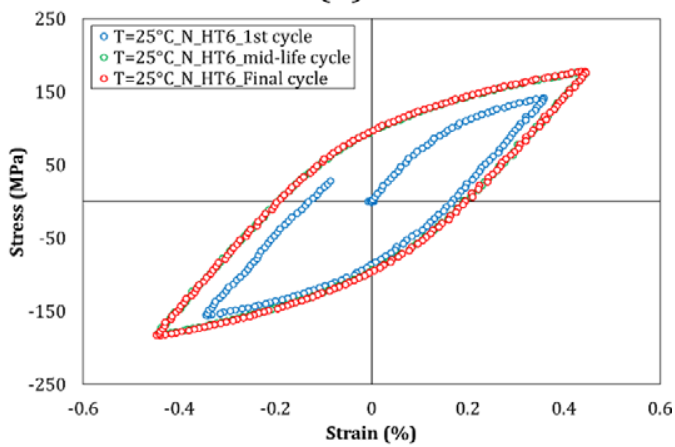

(d)

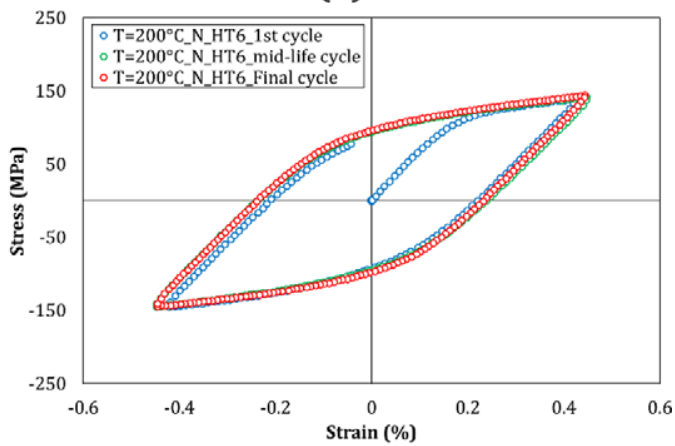

(f)

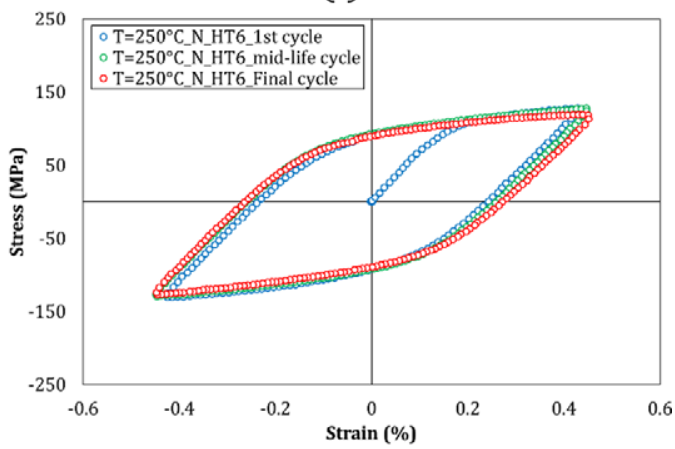

(h)

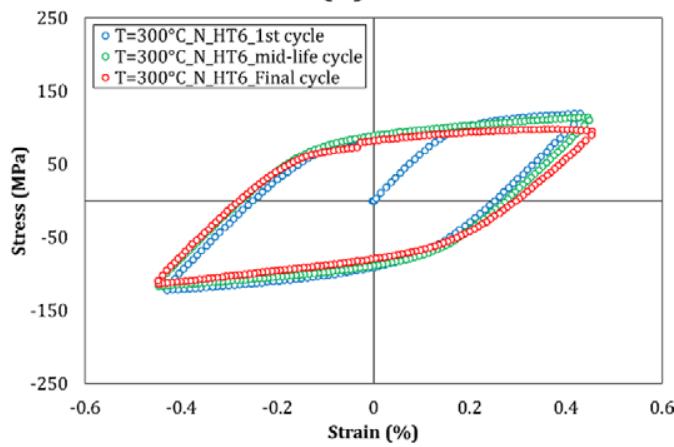

Figure 12. The stress-strain hysteresis for the first cycle, the mid-life cycle and the final cycle at the total strain amplitude of $0.45 \%$ and at the temperature of (a) $25^{\circ} \mathrm{C}$ for AlSi, (b) $25^{\circ} \mathrm{C}$ for AlSi_N_HT6, (c) $200^{\circ} \mathrm{C}$ for AlSi, (d) $200^{\circ} \mathrm{C}$ for AlSi_N_HT6, (e) $250^{\circ} \mathrm{C}$ for AlSi, (f) $250^{\circ} \mathrm{C}$ for AlSi_N_HT6, (g) $300^{\circ} \mathrm{C}$ for AlSi, and (h) $300^{\circ} \mathrm{C}$ for AlSi_N_HT6. 
(a)

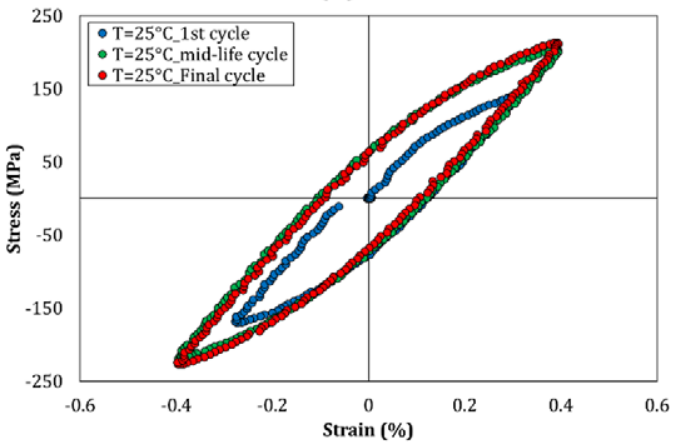

(c)

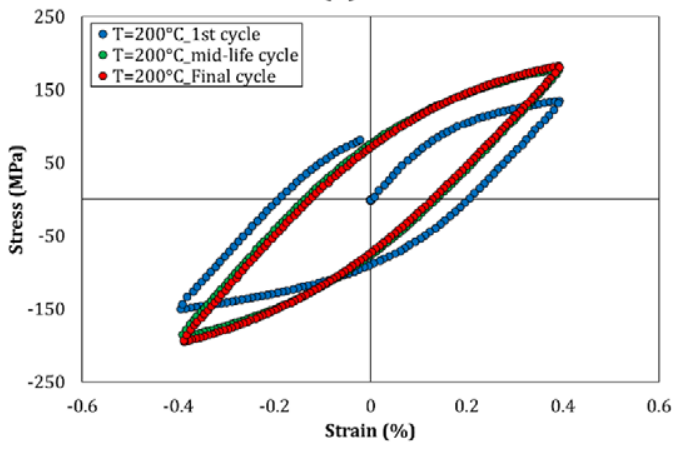

(e)

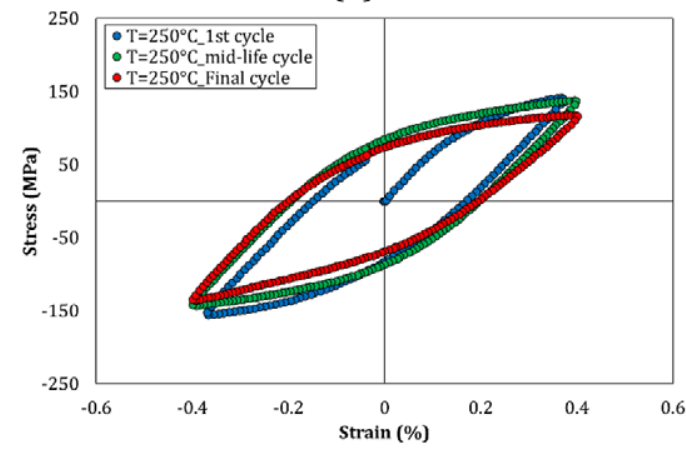

(g)

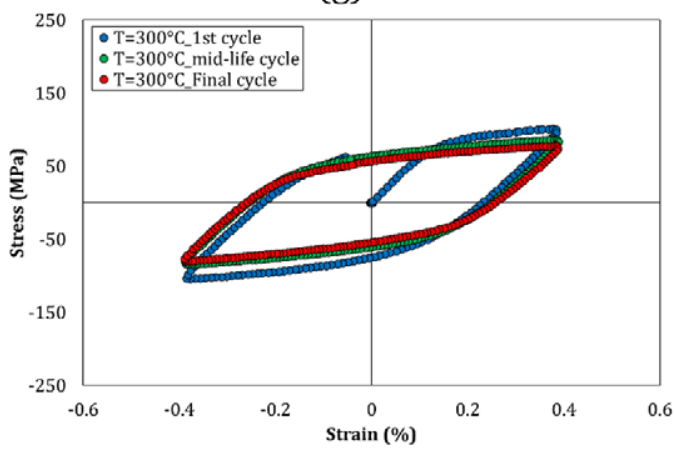

(b)

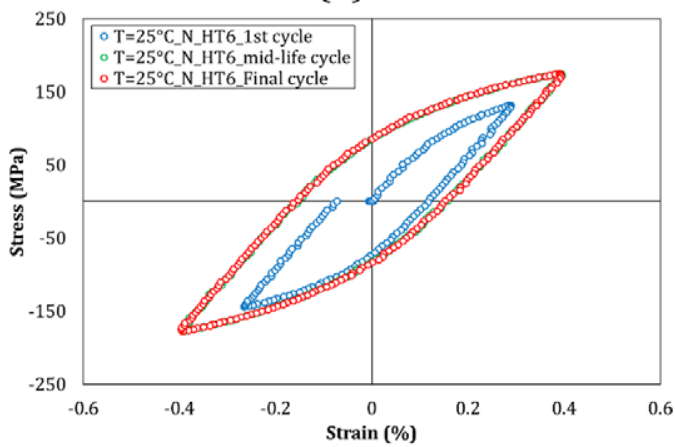

(d)

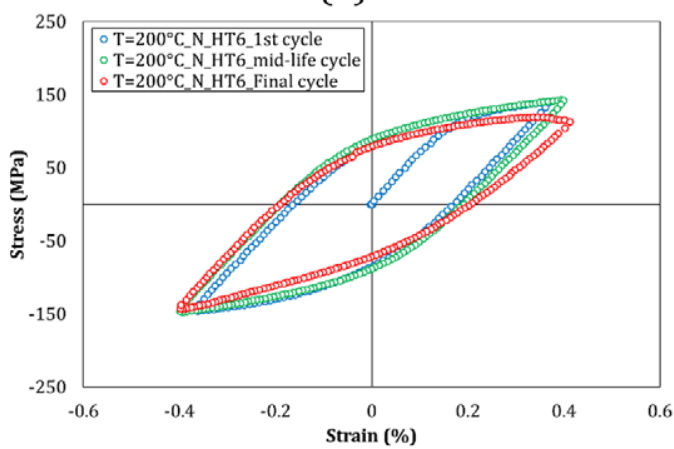

(f)

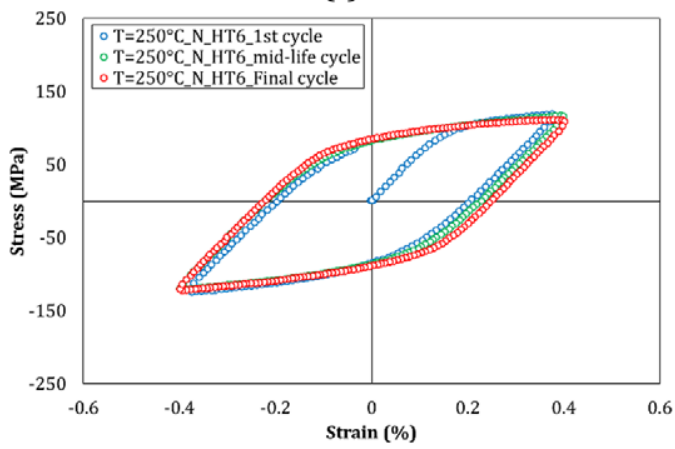

(h)

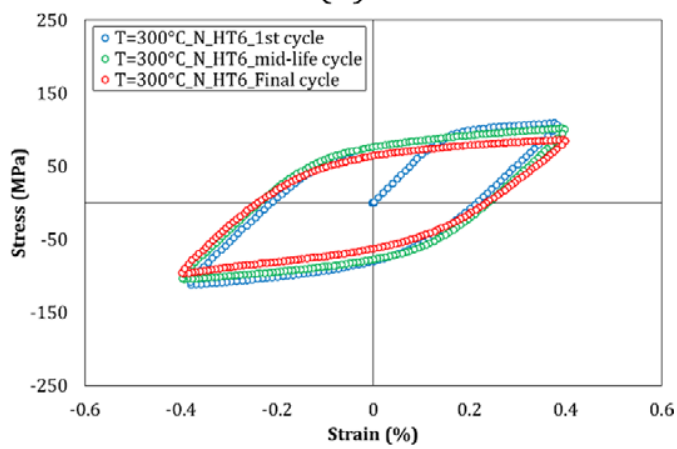

Figure 13. The stress-strain hysteresis for the first cycle, the mid-life cycle and the final cycle at the total strain amplitude of $0.40 \%$ and at the temperature of (a) $25^{\circ} \mathrm{C}$ for AlSi, (b) $25^{\circ} \mathrm{C}$ for AlSi_N_HT6, (c) $200^{\circ} \mathrm{C}$ for AlSi, (d) $200^{\circ} \mathrm{C}$ for AlSi_N_HT6, (e) $250^{\circ} \mathrm{C}$ for AlSi, (f) $250^{\circ} \mathrm{C}$ for AlSi_N_HT6, (g) $300^{\circ} \mathrm{C}$ for AlSi, and (h) $300^{\circ} \mathrm{C}$ for AlSi_N_HT6. 
(a)

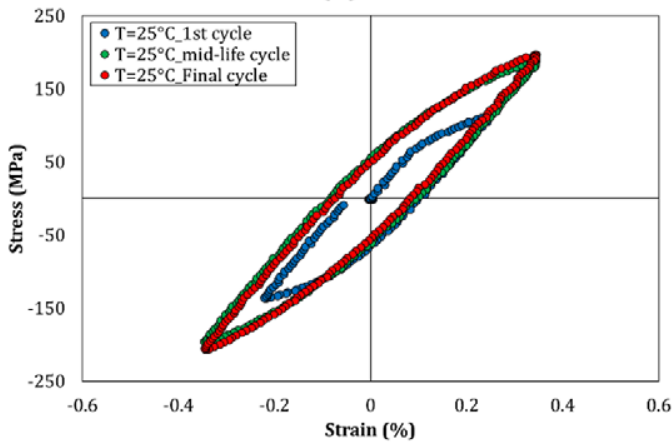

(c)

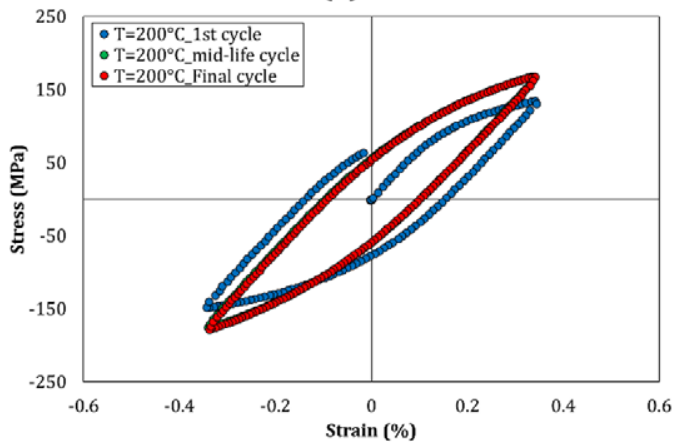

(e)

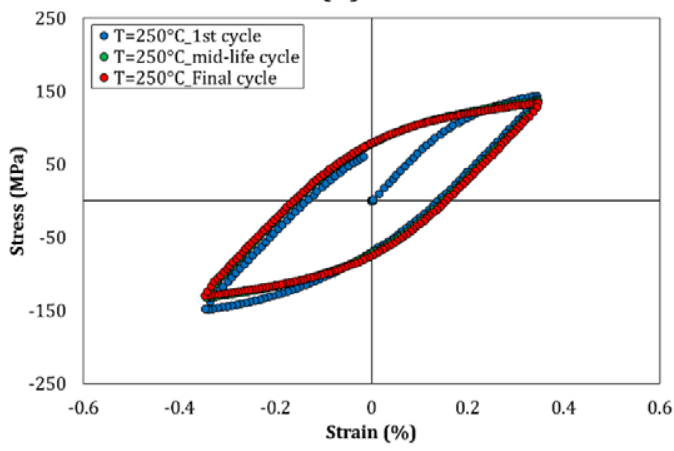

(g)

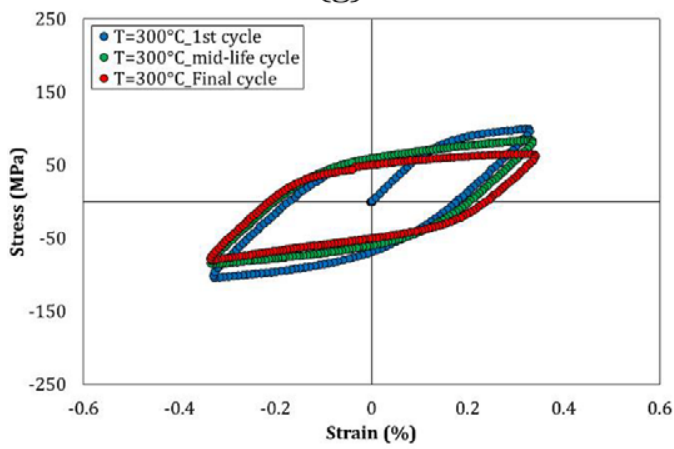

(b)

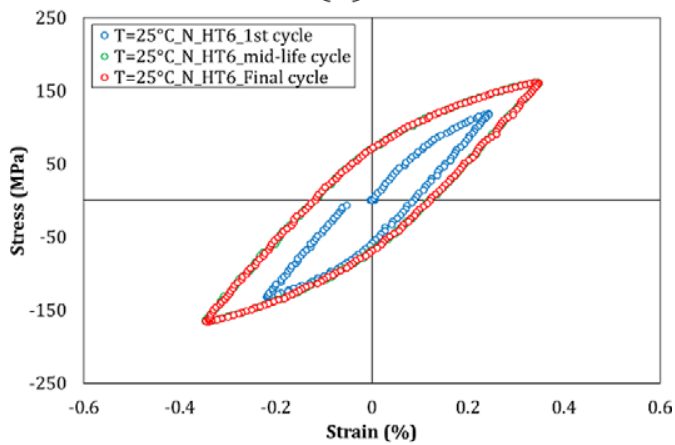

(d)

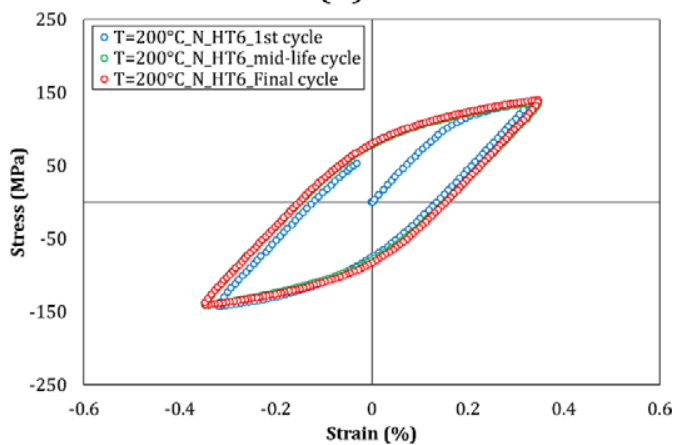

(f)

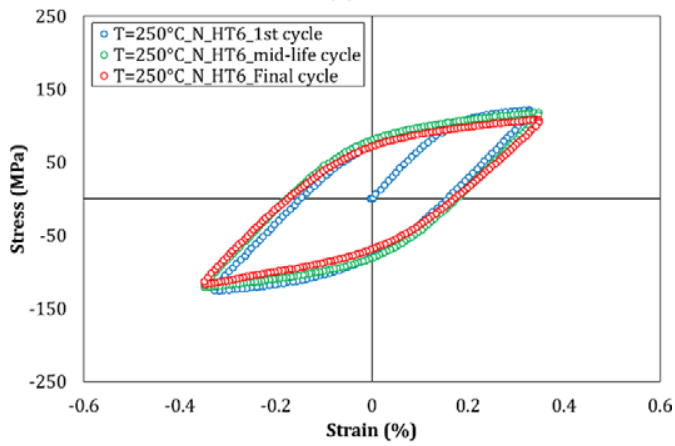

(h)

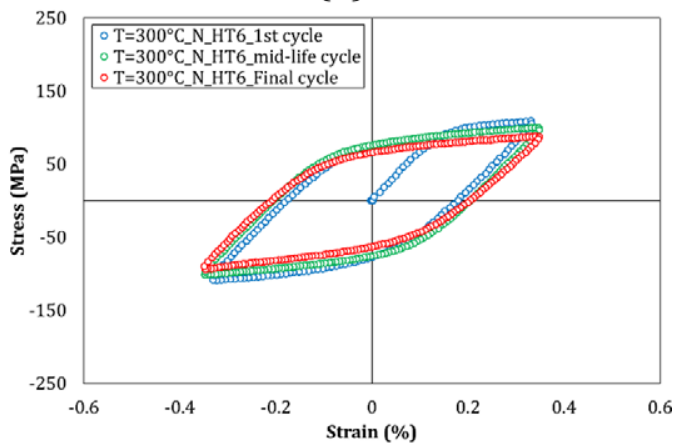

Figure 14. The stress-strain hysteresis for the first cycle, the mid-life cycle and the final cycle at the total strain amplitude of $0.35 \%$ and at the temperature of (a) $25^{\circ} \mathrm{C}$ for AISi, (b) $25^{\circ} \mathrm{C}$ for AISi_N_HT6, (c) $200^{\circ} \mathrm{C}$ for AISi, (d) $200^{\circ} \mathrm{C}$ for AISi_N_HT6, (e) $250^{\circ} \mathrm{C}$ for AlSi, (f) $250^{\circ} \mathrm{C}$ for AlSi_N_HT6, (g) $300^{\circ} \mathrm{C}$ for AlSi, and (h) $300^{\circ} \mathrm{C}$ for AlSi_N_HT6. 
(a)

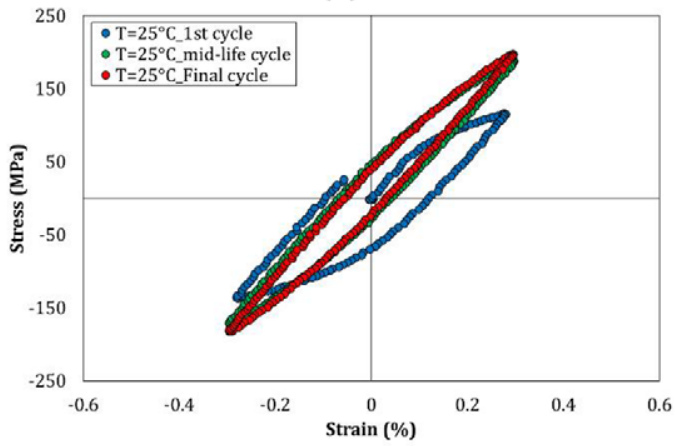

(c)

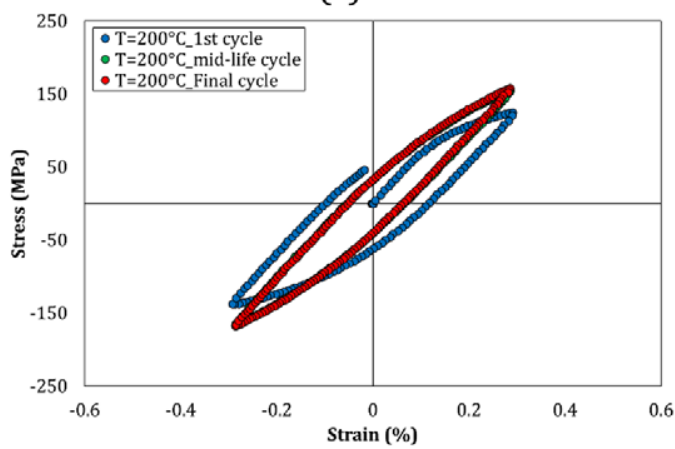

(e)

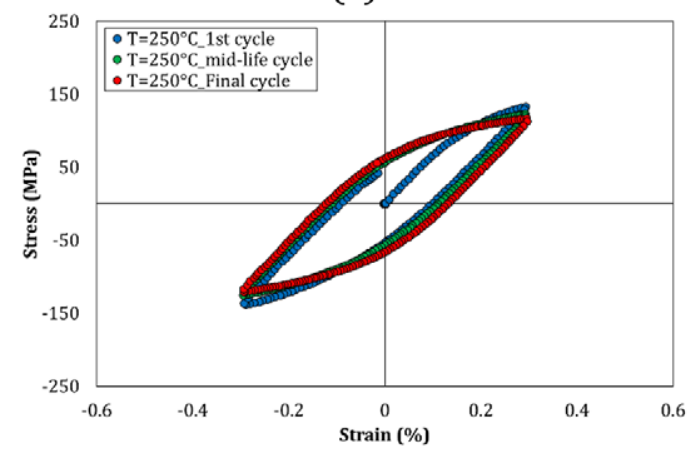

(g)

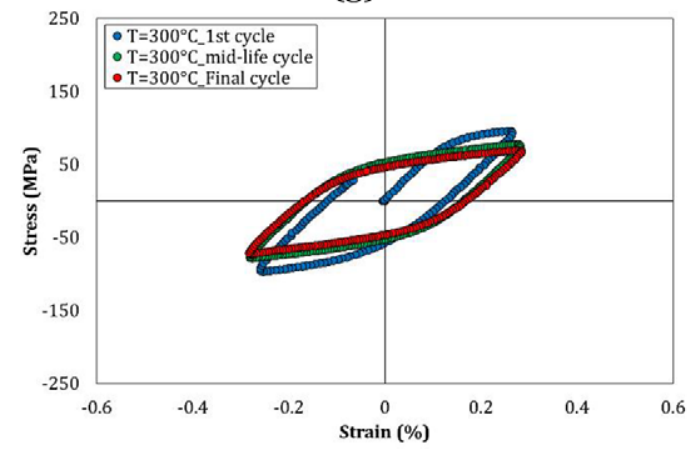

(b)

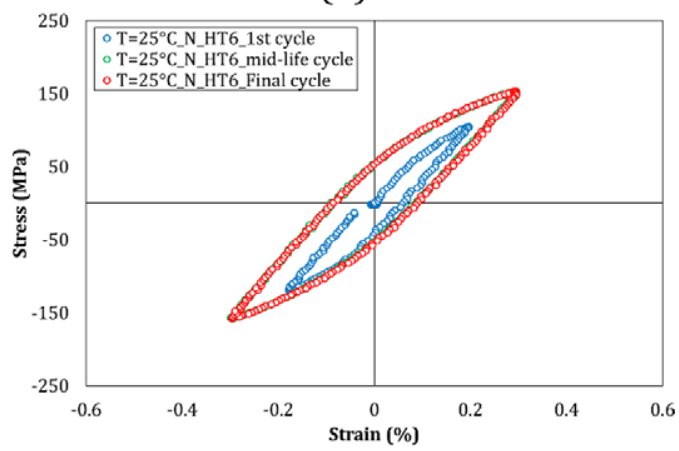

(d)

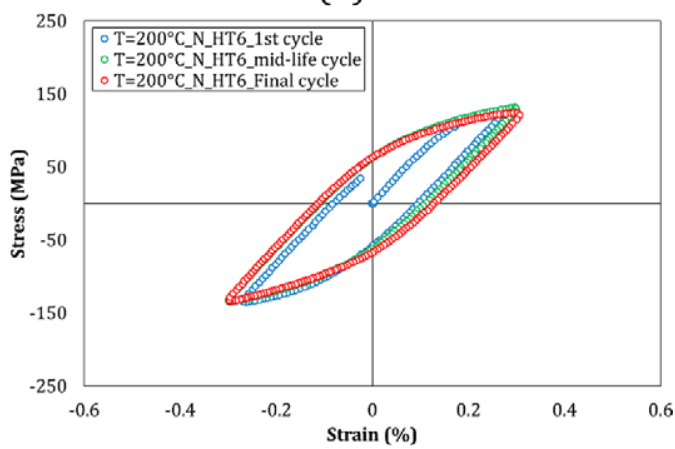

(f)

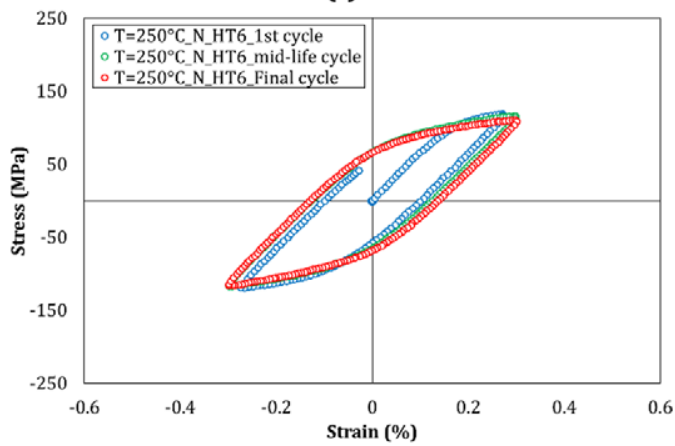

(h)

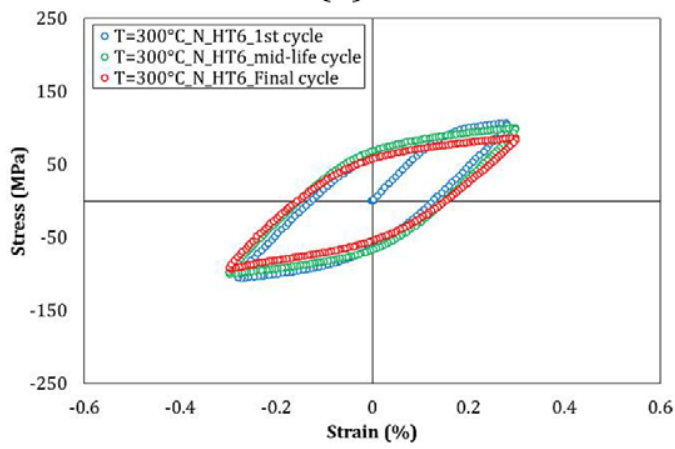

Figure 15. The stress-strain hysteresis for the first cycle, the mid-life cycle and the final cycle at the total strain amplitude of $0.30 \%$ and at the temperature of (a) $25^{\circ} \mathrm{C}$ for AISi, (b) $25^{\circ} \mathrm{C}$ for AlSi_N_HT6, (c) $200^{\circ} \mathrm{C}$ for AlSi, (d) $200^{\circ} \mathrm{C}$ for AlSi_N_HT6, (e) $250^{\circ} \mathrm{C}$ for AlSi, (f) $250^{\circ} \mathrm{C}$ for AlSi_N_HT6, (g) $300^{\circ} \mathrm{C}$ for AlSi, and (h) $300^{\circ} \mathrm{C}$ for AlSi_N_HT6. 
(a)

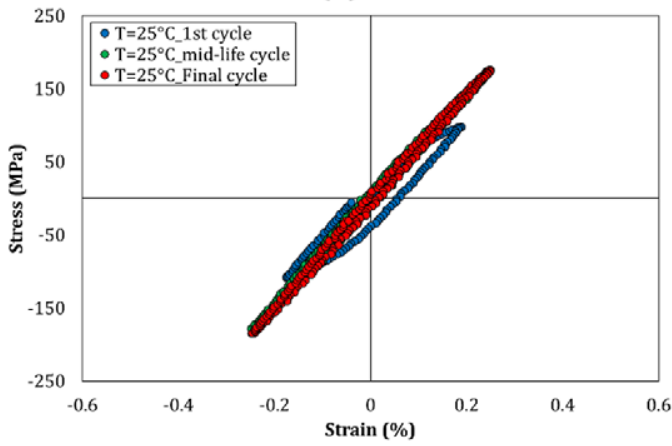

(c)

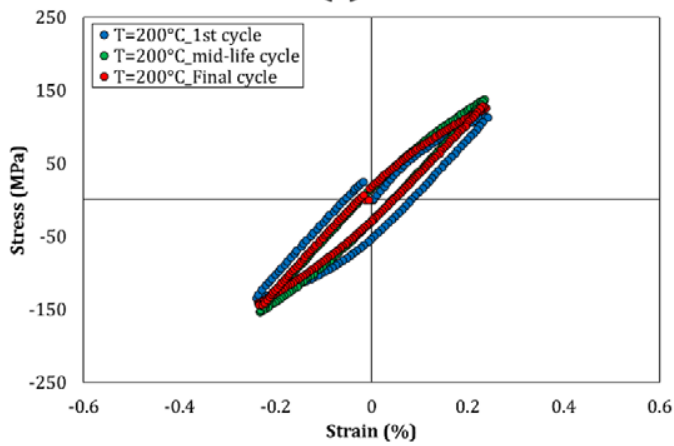

(e)

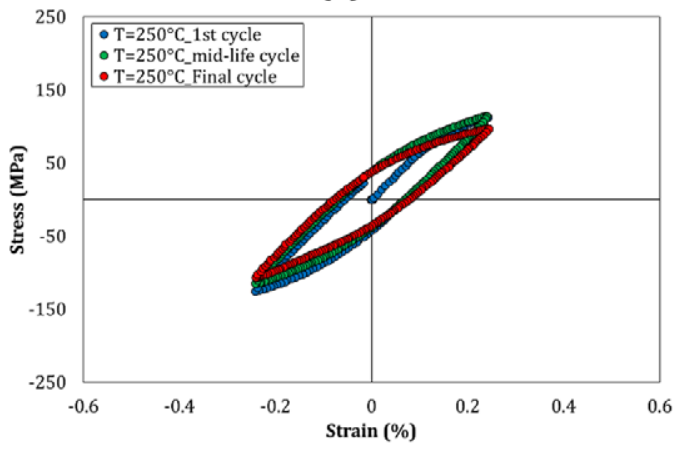

(g)

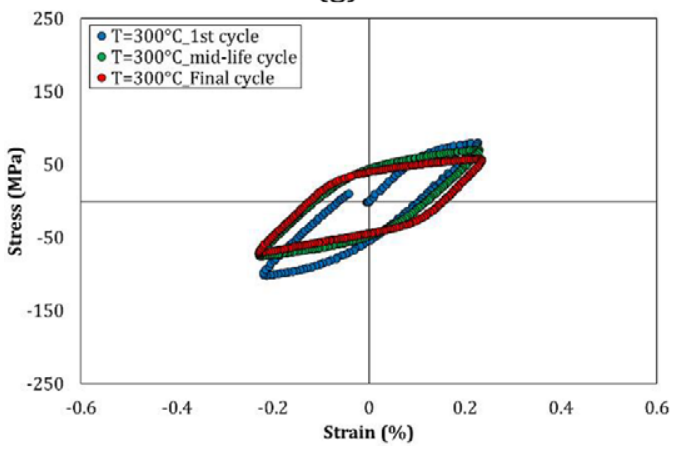

(b)

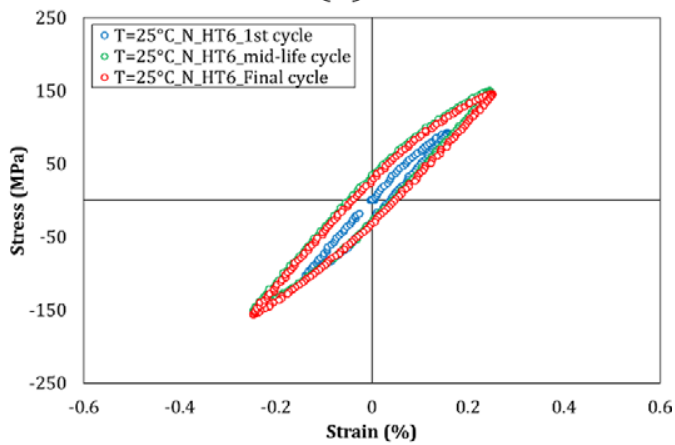

(d)

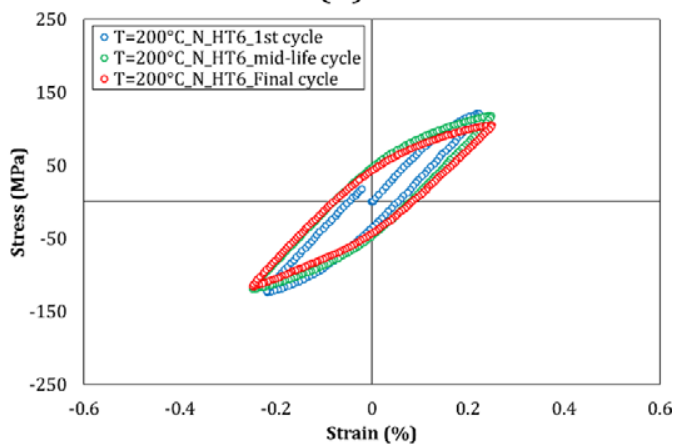

(f)

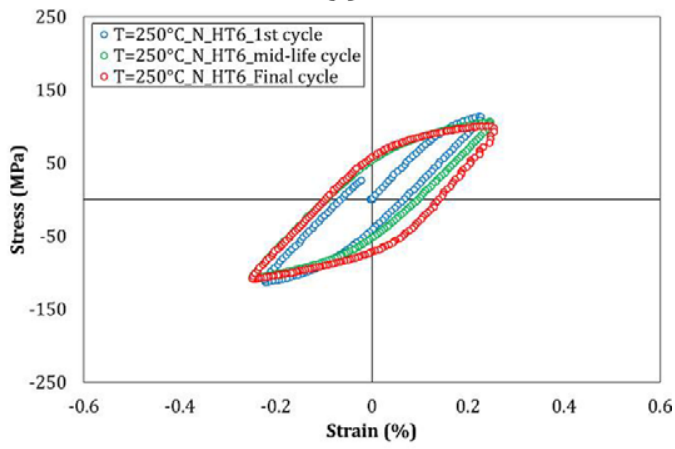

(h)

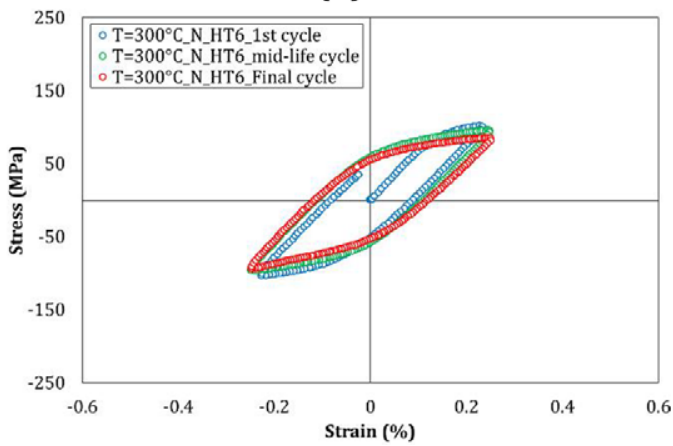

Figure 16. The stress-strain hysteresis for the first cycle, the mid-life cycle and the final cycle at the total strain amplitude of $0.25 \%$ and at the temperature of (a) $25^{\circ} \mathrm{C}$ for AlSi, (b) $25^{\circ} \mathrm{C}$ for AlSi_N_HT6, (c) $200^{\circ} \mathrm{C}$ for AlSi, (d) $200^{\circ} \mathrm{C}$ for AlSi_N_HT6, (e) $250^{\circ} \mathrm{C}$ for AlSi, (f) $250^{\circ} \mathrm{C}$ for AlSi_N_HT6, (g) $300^{\circ} \mathrm{C}$ for AlSi, and (h) $300^{\circ} \mathrm{C}$ for AlSi_N_HT6. 
(a)

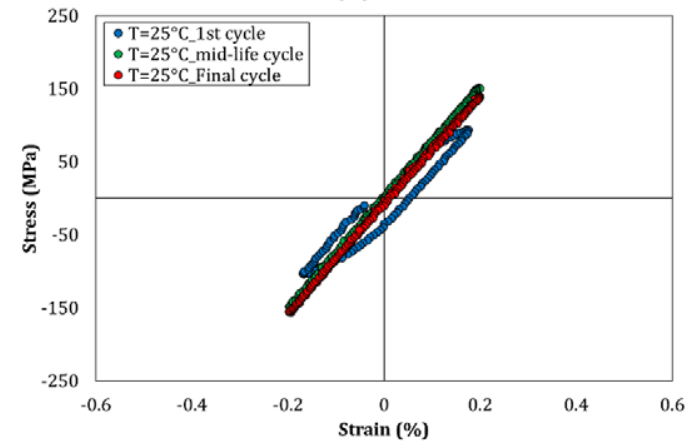

(c)

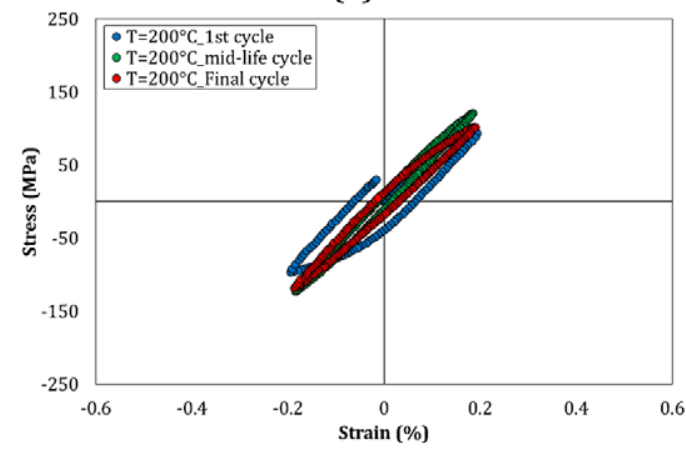

(e)

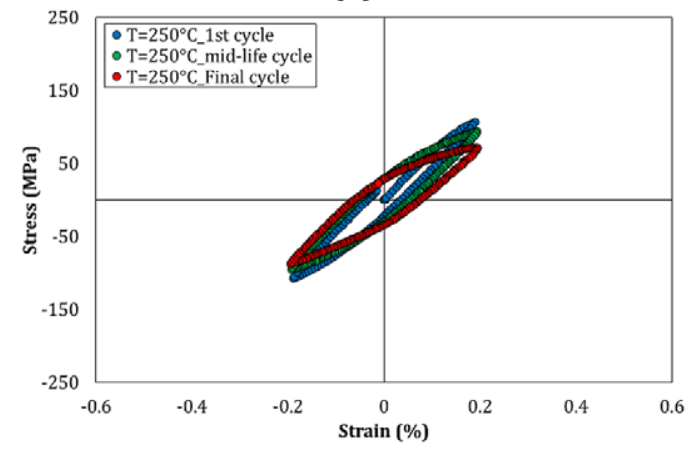

(g)

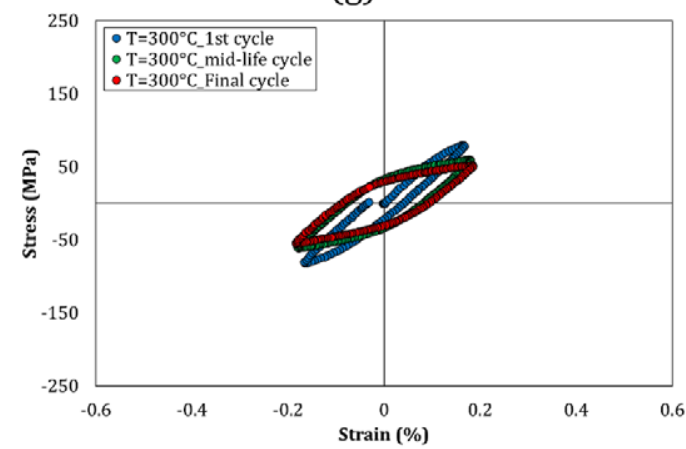

(b)

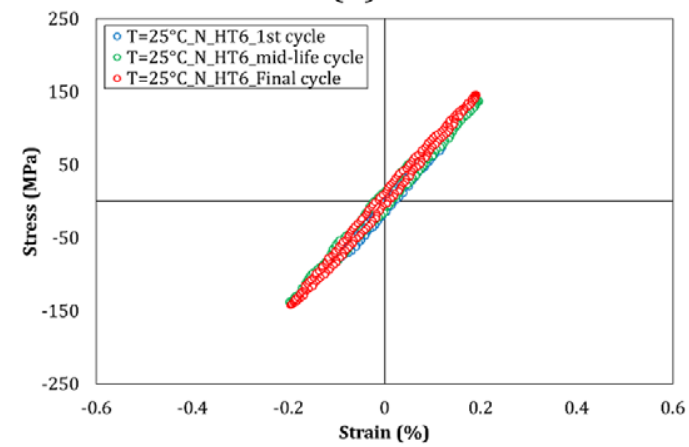

(d)

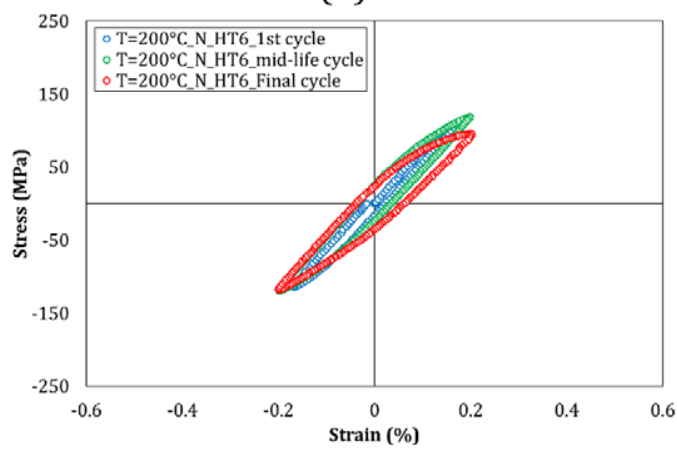

(f)

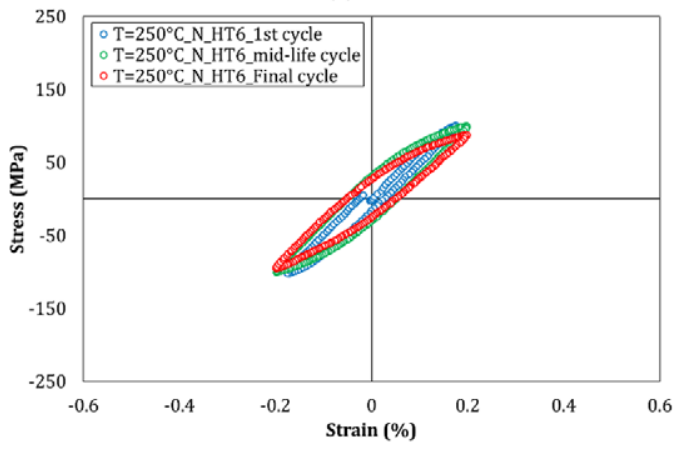

(h)

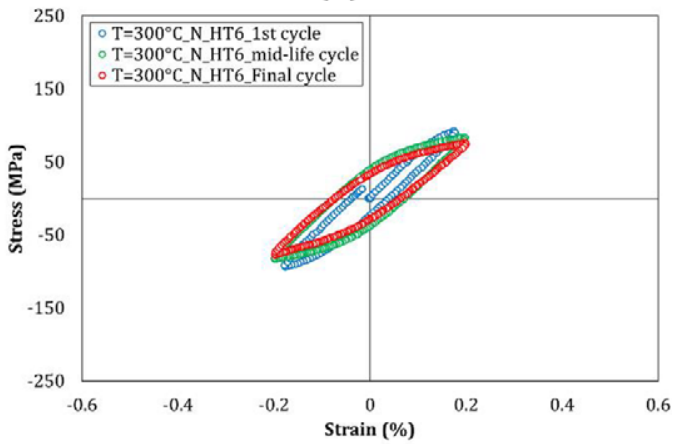

Figure 17. The stress-strain hysteresis for the first cycle, the mid-life cycle and the final cycle at the total strain amplitude of $0.20 \%$ and at the temperature of (a) $25^{\circ} \mathrm{C}$ for AlSi, (b) $25^{\circ} \mathrm{C}$ for AlSi_N_HT6, (c) $200^{\circ} \mathrm{C}$ for AlSi, (d) $200^{\circ} \mathrm{C}$ for AlSi_N_HT6, (e) $250^{\circ} \mathrm{C}$ for AlSi, (f) $250^{\circ} \mathrm{C}$ for AlSi_N_HT6, (g) $300^{\circ} \mathrm{C}$ for AlSi, and (h) $300^{\circ} \mathrm{C}$ for AlSi_N_HT6. 
Table 2. The cyclic behavior of AISi and AISi_N_HT6 using Ramberg-Osgood equation

\begin{tabular}{|c|c|c|c|c|c|}
\hline \multirow[b]{2}{*}{ Temperature $\left({ }^{\circ} \mathrm{C}\right)$} & \multirow[b]{2}{*}{$\varepsilon_{a, t}(\%)$} & \multicolumn{2}{|c|}{$\mathrm{AlSi}$} & \multicolumn{2}{|c|}{ AlSi_N_HT6 } \\
\hline & & Experiment & Ramberg-Osgood & Experiment & Ramberg-Osgood \\
\hline \multirow[t]{6}{*}{25} & 0.45 & Hardening & Hardening & Hardening & Hardening \\
\hline & 0.40 & Hardening & Hardening & Hardening & Hardening \\
\hline & 0.35 & Hardening & Hardening & Hardening & Hardening \\
\hline & 0.30 & Hardening & Hardening & Hardening & Hardening \\
\hline & 0.25 & Hardening & Hardening & Hardening & Hardening \\
\hline & 0.20 & Hardening & Hardening & Hardening & Hardening \\
\hline \multirow[t]{6}{*}{200} & 0.45 & Softening & Hardening & Softening & Hardening \\
\hline & 0.40 & Softening & Hardening & Softening & Hardening \\
\hline & 0.35 & Softening & Hardening & Softening & Hardening \\
\hline & 0.30 & Softening & Hardening & Softening & Hardening \\
\hline & 0.25 & Softening & Hardening & Softening & Hardening \\
\hline & 0.20 & Softening & Hardening & Softening & Hardening \\
\hline \multirow[t]{6}{*}{300} & 0.45 & Softening & Softening & Softening & Hardening \\
\hline & 0.40 & Softening & Softening & Softening & Hardening \\
\hline & 0.35 & Softening & Softening & Softening & Hardening \\
\hline & 0.30 & Softening & Softening & Softening & Hardening \\
\hline & 0.25 & Softening & Softening & Softening & Hardening \\
\hline & 0.20 & Softening & Softening & Softening & Hardening \\
\hline
\end{tabular}

Table 3. The Ramberg-Osgood parameters

\begin{tabular}{|c|c|c|c|c|c|}
\hline Specimen & Temperature $\left({ }^{\circ} \mathrm{C}\right)$ & $n^{\prime}(-)$ & $K^{\prime}(\mathrm{MPa})$ & Average error (\%) & $\begin{array}{c}\text { Maximum error } \\
(\%)\end{array}$ \\
\hline \multirow[t]{3}{*}{ AlSi } & 25 & 0.3962 & 295.5548 & 4.57 & 10.83 \\
\hline & 250 & 0.4547 & 213.2364 & 5.96 & 14.04 \\
\hline & 300 & 0.4073 & 128.2705 & 8.90 & 19.19 \\
\hline \multirow[t]{3}{*}{ AISi_N_HT6 } & 25 & 0.3353 & 237.2114 & 3.39 & 4.67 \\
\hline & 250 & 0.3042 & 163.7408 & 4.30 & 11.45 \\
\hline & 300 & 0.3865 & 155.7142 & 7.67 & 16.38 \\
\hline
\end{tabular}


Table 4. The amount and the rate of the cyclic hardening/softening behaviors, separately at various temperatures

\begin{tabular}{|c|c|c|c|c|c|}
\hline \multirow[b]{2}{*}{$T\left({ }^{\circ} \mathrm{C}\right)$} & \multirow[b]{2}{*}{$\varepsilon_{a, t}(\%)$} & \multicolumn{2}{|c|}{ AlSi } & \multicolumn{2}{|c|}{ AISi_N_HT6 } \\
\hline & & $A_{\mathrm{H} / \mathrm{S}}(\%)$ & $R_{\mathrm{H} / \mathrm{s}}(\% /$ cycle $)$ & $A_{\mathrm{H} / \mathrm{S}}(\%)$ & $\begin{array}{c}R_{\mathrm{H} / \mathrm{S}} \\
\text { (\%/cycle) }\end{array}$ \\
\hline \multirow[t]{6}{*}{25} & 0.45 & 51.7984 & 0.8633 & 25.2124 & 0.0840 \\
\hline & 0.40 & 61.3428 & 0.3067 & 33.1011 & 0.6620 \\
\hline & 0.35 & 65.9113 & 0.4514 & 36.6791 & 0.1834 \\
\hline & 0.30 & 62.5179 & 0.1514 & 46.5001 & 0.2325 \\
\hline & 0.25 & 77.7790 & 0.0343 & 61.3963 & 0.0608 \\
\hline & 0.20 & 59.4213 & 0.0036 & 79.2968 & 0.0267 \\
\hline \multirow[t]{6}{*}{200} & 0.45 & 4.9803 & 0.0249 & 2.0777 & 0.0208 \\
\hline & 0.40 & 33.2951 & 0.2921 & 2.4225 & 0.0484 \\
\hline & 0.35 & 25.3493 & 0.1267 & 1.7723 & 0.0044 \\
\hline & 0.30 & 24.9153 & 0.0415 & 2.5956 & 0.0043 \\
\hline & 0.25 & 20.1348 & 0.0015 & -2.1651 & -0.0002 \\
\hline & 0.20 & 29.1779 & 0.0013 & 7.4523 & 0.0019 \\
\hline \multirow[t]{6}{*}{250} & 0.45 & -2.0153 & -0.0101 & -0.1958 & -0.0039 \\
\hline & 0.40 & -2.7934 & -0.0093 & -1.5744 & -0.0031 \\
\hline & 0.35 & -5.0461 & -0.0126 & -3.2081 & -0.0053 \\
\hline & 0.30 & -7.8147 & -0.0087 & -2.3980 & -0.0120 \\
\hline & 0.25 & 0.6827 & 0.0007 & -6.2010 & -0.0016 \\
\hline & 0.20 & -12.3553 & -0.0012 & -6.7004 & -0.0008 \\
\hline \multirow[t]{6}{*}{300} & 0.45 & -15.1841 & -0.0190 & -4.1088 & -0.0587 \\
\hline & 0.40 & -14.4913 & -0.0145 & -6.7408 & -0.0225 \\
\hline & 0.35 & -15.4691 & -0.0155 & -8.1221 & -0.0162 \\
\hline & 0.30 & -18.8369 & -0.0047 & -6.4970 & -0.0162 \\
\hline & 0.25 & -11.3548 & -0.0023 & -6.0049 & -0.0120 \\
\hline & 0.20 & -24.4776 & -0.0012 & -10.0011 & -0.0034 \\
\hline
\end{tabular}


Table 5. The amount and the rate of the cyclic hardening/softening behaviors, separately at various values of the total strain amplitude

\begin{tabular}{|c|c|c|c|c|c|}
\hline \multirow[b]{2}{*}{$\varepsilon_{a, t}(\%)$} & \multirow[b]{2}{*}{$T\left({ }^{\circ} \mathrm{C}\right)$} & \multicolumn{2}{|c|}{ AlSi } & \multicolumn{2}{|c|}{ AlSi_N_HT6 } \\
\hline & & $A_{\mathrm{H} / \mathrm{s}}(\%)$ & $R_{\mathrm{H} / \mathrm{s}}(\% /$ cycle $)$ & $A_{\mathrm{H} / \mathrm{s}}(\%)$ & $\begin{array}{c}R_{\mathrm{H} / \mathrm{S}} \\
\text { (\%/cycle) }\end{array}$ \\
\hline \multirow[t]{4}{*}{0.45} & 25 & 51.7984 & 0.8633 & 25.2124 & 0.0840 \\
\hline & 200 & 4.9803 & 0.0249 & 2.0777 & 0.0208 \\
\hline & 250 & -2.0153 & -0.0101 & -0.1958 & -0.0039 \\
\hline & 300 & -15.1841 & -0.0190 & -4.1088 & -0.0587 \\
\hline \multirow[t]{4}{*}{0.40} & 25 & 61.3428 & 0.3067 & 33.1011 & 0.6620 \\
\hline & 200 & 33.2951 & 0.2921 & 2.4225 & 0.0484 \\
\hline & 250 & -2.7934 & -0.0093 & -1.5744 & -0.0031 \\
\hline & 300 & -14.4913 & -0.0145 & -6.7408 & -0.0225 \\
\hline \multirow[t]{4}{*}{0.35} & 25 & 65.9113 & 0.4514 & 36.6791 & 0.1834 \\
\hline & 200 & 25.3493 & 0.1267 & 1.7723 & 0.0044 \\
\hline & 250 & -5.0461 & -0.0126 & -3.2081 & -0.0053 \\
\hline & 300 & -15.4691 & -0.0155 & -8.1221 & -0.0162 \\
\hline \multirow[t]{4}{*}{0.30} & 25 & 62.5179 & 0.1514 & 46.5001 & 0.2325 \\
\hline & 200 & 24.9153 & 0.0415 & 2.5956 & 0.0043 \\
\hline & 250 & -7.8147 & -0.0087 & -2.3980 & -0.0120 \\
\hline & 300 & -18.8369 & -0.0047 & -6.4970 & -0.0162 \\
\hline \multirow[t]{4}{*}{0.25} & 25 & 77.7790 & 0.0343 & 61.3963 & 0.0608 \\
\hline & 200 & 20.1348 & 0.0015 & -2.1651 & -0.0002 \\
\hline & 250 & 0.6827 & 0.0007 & -6.2010 & -0.0016 \\
\hline & 300 & -11.3548 & -0.0023 & -6.0049 & -0.0120 \\
\hline \multirow[t]{4}{*}{0.20} & 25 & 59.4213 & 0.0036 & 79.2968 & 0.0267 \\
\hline & 200 & 29.1779 & 0.0013 & 7.4523 & 0.0019 \\
\hline & 250 & -12.3553 & -0.0012 & -6.7004 & -0.0008 \\
\hline & 300 & -24.4776 & -0.0012 & -10.0011 & -0.0034 \\
\hline
\end{tabular}

Acknowledgments. This research is financed by the Austrian Agency for International Cooperation in Education and Research (OeAD) and the Ministry of Science, Research and Technology of Iran, and also Kharazmi University in Iran, through the IMPULSE funding program. In addition, authors tend to thank the Motorsazi Pooya Neyestanak (MPN) Company, in Iran for casting and raw materials.

Supplementary Materials. To view supplementary material for this article, please visit http://doi.org/10.1017/exp.2021.32.

Data availability statement. The data that support the findings of this article are available based on the request from the corresponding author. In general, the data are not publicly available due to the privacy of research participants.

Conflict of interest. For this research, there is no conflict of interest for all authors. 
Authorship contributions. Conceptualization, M.A., G.W.; Data curation, H.B., B.S.; Formal analysis, H.B.; Funding acquisition, M.A., F.G.; Investigation, M.A., H.B.; Methodology, M.A., G.W.; Project administration, M.A., F.G.; Resources, M.A., F.G.; Software, H.B., G.W., B.S.; Supervision, M.A., F.G.; Validation, M.A, G.W.; Visualization, M.A., F.G.; Writing-original draft, H.B.; Writing-review \& editing, M.A., B.S.

\section{References}

Azadi, M. (2013). Effects of strain rate and mean strain on cyclic behavior of aluminum alloys under isothermal and thermomechanical fatigue loadings. International Journal of Fatigue, 47, 148-153.

Azadi, M. (2017). Cyclic thermo-mechanical stress, strain and continuum damage behaviors in light alloys during fatigue lifetime considering heat treatment effect. International Journal of Fatigue, 99, 303-314.

Azadi, M., Bahmanabadi, H., Gruen, F., \& Winter, G. (2020). Evaluation of tensile and low-cycle fatigue properties at elevated temperatures in piston aluminum-silicon alloys with and without nano-clay-particles and heat treatment. Materials Science and Engineering: A, 788, 139497.

Azadi, M., \& Shirazabad, M. M. (2013). Heat treatment effect on thermo-mechanical fatigue and low cycle fatigue behaviors of A356.0 aluminum alloy. Materials \& Design, 45, 279-285.

Branco, R., Costa, J. D., Borrego, L. P., Wu, S. C., Long, X. Y., \& Zhang, F. C. (2019). Effect of strain ratio on cyclic deformation behavior of 7050-T6 aluminum alloy. International Journal of Fatigue, 129, 105234.

Cai, C., Geng, H., \& Zhang, Z. (2018). Temperature-dependent cyclic response and microstructure of $\mathrm{AlSi} 10 \mathrm{Mg}(\mathrm{Cu})$ alloy. Materials Characterization, 141, 148-155.

Do Lee, C., \& Yoo, S. J. (2014). Dependence of fatigue life of low-pressure die-cast A356 aluminum alloy on microporosity variation. Metals and Materials International, 20(4), 601-612.

Fan, K. L., Liu, X. S., He, G. Q., \& Chen, H. (2015). Elevated temperature low cycle fatigue of a gravity casting Al-Si-Cu alloy used for engine cylinder heads. Materials Science and Engineering: A, 632, 127-136.

Felfeli, M., Azadi, M., \& Farrahi, G. H. (2015). Constitutive modeling of elastic-visco-plastic behaviors in aluminum alloys subjected to cyclic loadings at various strain rates. The Journal of Strain Analysis for Engineering Design, 50(2), 103-124.

Guo, B., Zhang, W., Li, S., \& Wang, X. (2017). High-temperature low cycle fatigue and creep-fatigue behavior of a casting Al9Si-CuMg alloy used for cylinder heads. Materials Science and Engineering: A, 700, 397-405.

Kim, K. S., Sung, S. Y., Han, B. S., Park, J. C., \& Lee, K. A. (2015). High-temperature, low-cycle fatigue behavior of an Al-MgSi based heat-resistant aluminum alloy. Metals and Materials International, 21(6), 1000-1005.

Li, P., Li, H., Liang, X., Che, Y., Zhan, X., \& Huang, L. (2018). Effect of isothermal and non-isothermal ageing on the low cycle fatigue behavior of an Al-Cu-Mg-Si forging alloy. Materials Characterization, 144, 378-386.

Liu, J., Zhang, Q., Zuo, Z., Xiong, Y., Ren, F., \& Volinsky, A. A. (2013). Microstructure evolution of Al-12Si-CuNiMg alloy under high-temperature low cycle fatigue. Materials Science and Engineering: A, 574, 186-190.

Luk, M. J., Mirza, F. A., Chen, D. L., Ni, D. R., Xiao, B. L., \& Ma, Z. Y. (2015). Low cycle fatigue of SiCp reinforced AA2009 composites. Materials and Design, 66, 274-283.

Song, M. S., Kong, Y. Y., Ran, M. W., \& She, Y. C. (2011). Cyclic stress-strain behavior and low cycle fatigue life of cast A356 alloys. International Journal of Fatigue, 33(12), 1600-1607.

Cite this article: Azadi M, Bahmanabadi H, Gruen F, Winter G, Seisenbacher B (2022). Cyclic hardening/softening experimental data in nano-clay-composite and aluminum alloy under high-temperature strain-controlled loading.

Experimental Results, 3, e6, 1-32. https://doi.org/10.1017/exp.2021.32 


\title{
Peer Reviews
}

\author{
Reviewing editor: Dr. Mert Celikin \\ University College Dublin, Mechanical and Materials Engineering, Dublin, Ireland, 4
}

This article has been accepted because it is deemed to be scientifically sound, has the correct controls, has appropriate methodology and is statistically valid, and has been sent for additional statistical evaluation and met required revisions.

doi:10.1017/exp.2021.32.pr1

\section{Review 1: Cyclic Hardening/Softening Behaviors in Nano-Clay-Composite and Aluminum Alloy under High-Temperature Strain-Controlled Loading}

\author{
Reviewer: Dr. Kyriakos Kourousis if
}

Date of review: 19 October 2021

(c) The Author(s), 2022. Published by Cambridge University Press. This is an Open Access article, distributed under the terms of the Creative Commons Attribution licence (http://creativecommons.org/licenses/by/4.0), which permits unrestricted re-use, distribution and reproduction, provided the original article is properly cited.

Conflict of interest statement. Reviewer declares none

Comments to the Author: This experimental study offers very useful results for the characterisation of the cyclic behaviour of the subject matter alloys. It can enrich the published literature in this area. The research has been conducted correctly but English requires drastic improvement, specifically in relation to syntax, grammar and accurate use of language in many instances - i.e. 'enhancement of temperature' should be 'increase of temperature', 'effect of temperature was higher...', 'Researches about cyclic behaviors' should be 'research studies on ...', etc etc. The poor use of English affects greatly the readability of this paper. Also, the authors are requested to clarify/amend the following issues:

- The methodology section should be expanded to include further details on the test configuration, material, etc. It is currently very briefly, lacking important information.

- Figure 3 and 4 should be broken down to separate figures, showing clearly the different features and avoid using the strain level 'boxed' indicators.

- Figure $6,7,8,9,10,11,12,13,14,15,16$ and 17: Using circles for the data points makes visualisation difficult. Please use dots or dashes instead.

- Table 3 results: Can the authors please comment (add further details in the paper) on the increasing Average Error\% with the increase of temperature? For example, is there an influence of the RambergOsgood parameters' choice?

- Table 4 and 5: Is four decimal points' accuracy necessary? If yes please justify, if not please reduce to two decimals.

- The results are very lightly discussed in many instances, despite the extensive array of data presented in the paper. The authors should expand the discussion throughout. That includes expanding the discussion on limitations.

- Many of the bullet points in the Conclusions section are unclear - i.e. 'Under the same strain amplitude, the amount of cyclic hardening decreased by temperature increasing.' which is the same strain amplitude in this case?). The authors are requested to rewrite this section. 
Presentation

2.7

Is the article written in clear and proper English? (30\%)

Is the data presented in the most useful manner? (40\%) 3/5

Does the paper cite relevant and related articles appropriately? (30\%)

Context

3.5

Does the title suitably represent the article? (25\%)

Does the abstract correctly embody the content of the article? (25\%)

Does the introduction give appropriate context? (25\%)

Is the objective of the experiment clearly defined? (25\%)

Analysis

Is the conclusion consistent with the results and discussion? (40\%)

Are the limitations of the experiment as well as the contributions of the experiment clearly outlined? $(20 \%)$ 


\section{Review 2: Cyclic Hardening/Softening Behaviors in Nano-Clay-Composite and Aluminum Alloy under High-Temperature Strain-Controlled Loading}

Reviewer: Dr. Kun Liu

Date of review: 16 October 2021

(C) The Author(s), 2022. Published by Cambridge University Press. This is an Open Access article, distributed under the terms of the Creative Commons Attribution licence (http://creativecommons.org/licenses/by/4.0), which permits unrestricted re-use, distribution and reproduction, provided the original article is properly cited.

Conflict of interest statement. Reviewer declares none

Comments to the Author: The background for this work is not clear stated in the introduction part that why the compostied is used and what's the advantage/disadvantage compared with Al-Si cast alloys. Besides, there is no explanation on the general evolution of LCF with tempeature and strain amplitude, which must relate to the evolution of precipiates. Meanwhile, no explaination on the differences of LCF between two different materials, which should relate the reforcement particles. Therefore, I would like to reject it from the view of point of materials science.

\section{Score Card}

Presentation

3.0

Is the article written in clear and proper English? (30\%)

Is the data presented in the most useful manner? (40\%)

Does the paper cite relevant and related articles appropriately? (30\%)

Context

3.0

Does the title suitably represent the article? (25\%)

Does the abstract correctly embody the content of the article? (25\%)

Does the introduction give appropriate context? (25\%)

Is the objective of the experiment clearly defined? (25\%)

Analysis

Does the discussion adequately interpret the results presented? (40\%)

Is the conclusion consistent with the results and discussion? (40\%)

Are the limitations of the experiment as well as the contributions of the experiment clearly outlined? (20\%) 


\section{Review 3: Cyclic Hardening/Softening Behaviors in Nano-Clay-Composite and Aluminum Alloy} under High-Temperature Strain-Controlled Loading

Reviewer: Dr. P. Narayanasamy

Date of review: 11 November 2021

(C) The Author(s), 2022. Published by Cambridge University Press. This is an Open Access article, distributed under the terms of the Creative Commons Attribution licence (http://creativecommons.org/licenses/by/4.0), which permits unrestricted re-use, distribution and reproduction, provided the original article is properly cited.

Conflict of interest statement. Nil

Comments to the Author: 1. Literature survey is not included.

\section{Score Card}

Presentation

4.0

Is the article written in clear and proper English? (30\%)

Is the data presented in the most useful manner? $(40 \%)$

Does the paper cite relevant and related articles appropriately? (30\%)

Context

3.8

Does the title suitably represent the article? (25\%)

Does the abstract correctly embody the content of the article? (25\%)

Does the introduction give appropriate context? (25\%)

Is the objective of the experiment clearly defined? (25\%)

Analysis

Does the discussion adequately interpret the results presented? (40\%)

Is the conclusion consistent with the results and discussion? (40\%)

Are the limitations of the experiment as well as the contributions of the experiment clearly outlined? $(20 \%)$ 